University of Louisville

ThinkIR: The University of Louisville's Institutional Repository

Electronic Theses and Dissertations

$5-2013$

\title{
Sex differences in violent school victimization : using self-control to understand variation in victimization.
}

Anthony Smith 1989-

University of Louisville

Follow this and additional works at: https://ir.library.louisville.edu/etd

\section{Recommended Citation}

Smith, Anthony 1989-, "Sex differences in violent school victimization : using self-control to understand variation in victimization." (2013). Electronic Theses and Dissertations. Paper 1346.

https://doi.org/10.18297/etd/1346

This Master's Thesis is brought to you for free and open access by ThinkIR: The University of Louisville's Institutional Repository. It has been accepted for inclusion in Electronic Theses and Dissertations by an authorized administrator of ThinkIR: The University of Louisville's Institutional Repository. This title appears here courtesy of the author, who has retained all other copyrights. For more information, please contact thinkir@louisville.edu. 


\title{
SEX DIFFERENCES IN VIOLENT SCHOOL VICTIMIZATION: USING SELF- CONTROL TO UNDERSTAND VARIATION IN VICTIMIZATION
}

\author{
By \\ Anthony Smith \\ B.S., University of Louisville 2011

\begin{abstract}
A Thesis
Submitted to the Faculty of the

College of Arts and Sciences of the University of Louisville in Partial Fulfillment of the Requirements for the Degree of
\end{abstract}

Master of Science

Department of Justice Administration

University of Louisville

Louisville, Kentucky

May 2013 
Copyright 2013 by Anthony Aaron Smith

All rights reserved 


\title{
SEX DIFFERENCES IN VIOLENT SCHOOL VICTIMIZATION: USING SELF-
} CONTROL TO UNDERSTAND VARIATION IN VICTIMIZATION

\author{
By
}

Anthony Aaron Smith

B.S., University of Louisville, 2011

A Thesis Approved on

April 20, 2013

By the following Thesis Committee:

George E. Higgins, Thesis Director

J. Price Foster

Seana Golder 


\section{DEDICATION AND ACKNOWLEDGEMENTS}

A thesis, as well as any other important achievement, is not an event that occurs in a vacuum. This work is the culmination of my entire academic career and is a testament to those that helped me along the way. Family, professors, and friends have constantly and consistently urged me forward in my educational endeavors.

I owe the greatest thanks to my mother, my father, and my grandmother for their

encouragement and patience for the difficulties that come with getting a child through college. My mother has been especially instrumental in my success, not only for her encouragement, but also for taking on the peripheral issues that come up during six years in college, which allowed me to stay focused and successful in what she thought was most important to building a better life: education.

I could not have gotten to where I am today if it were not for professors and staff in the justice administration department taking an interest in my future and opening my eyes to the possibilities beyond simply graduating. Dr. George Higgins, Dr. Deborah Keeling, Kim Hendricks, Dr. Teresa Hayden, and Dr. Price Foster have done so much for my educational career than just teach a subject or demonstrate a skill. These individuals took an interest and a chance on a stranger by offering me educational opportunities and personal guidance. It was not overlooked and will never be forgotten. From my experiences with all of these fine individuals, I have been able to grow so far beyond what I ever thought possible and now I realize that nothing is unobtainable. 


\title{
ASTRACT \\ SEX DIFFERENCES IN VIOLENT SCHOOL VICTIMIZATION: USING SELF- CONTROL TO UNDERSTAND VARIATION IN VICTIMIZATION
}

\author{
Anthony Aaron Smith
}

April 2, 2013

Violent victimization of students within the school environment has become a major issue to our school systems, administrators, teachers, and students. Despite this high rate of violent victimization, little is known about the individual predictors and whether they operate similarly for males and females. The present study utilizes an $8^{\text {th }}$ grade student sample to determine the predictive ability of self-control, deviant peer associations, age, sex, and race on violent school victimization. In addition, each of these items will have their predictive ability tested on males and females separately to examine whether the items are equally effective across biological sex. Findings indicate that selfcontrol, deviant peer associations, age, and race are significant predictors of violent victimization in the general model. The sex-specific models showed that only self-control and deviant peer associations were significant across sex. Policy implications for schools are addressed. 


\section{TABLE OF CONTENTS}

PAGE

ACKNOWLEDGEMENTS ............................................................. ii

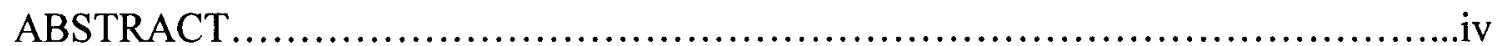

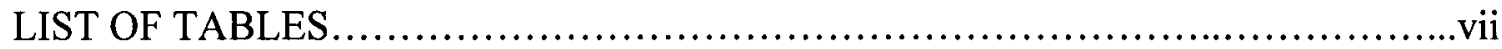

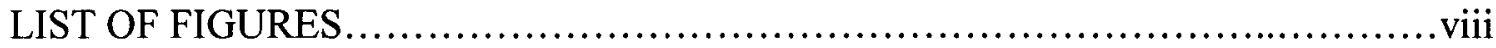

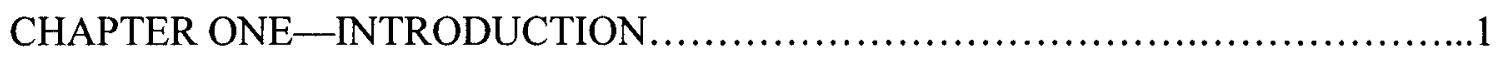

Statement of the Problem............................................................

Theoretical Perspective: The General Theory of Crime...........................4

Self-Control and Victimization...........................................

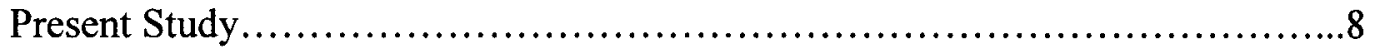

CHAPTER TWO-LITERATURE REVIEW .................................. 10

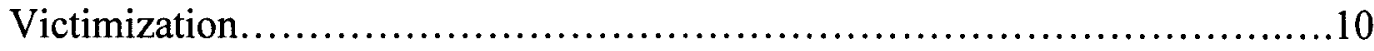

Parental Management.......................................................

Sex Differences in Parental Management.....................................13

Self-Control across Sex Lines.................................................

Self-Control and Victimization..............................................

Deviant Peer Association and Self-Control.....................................20

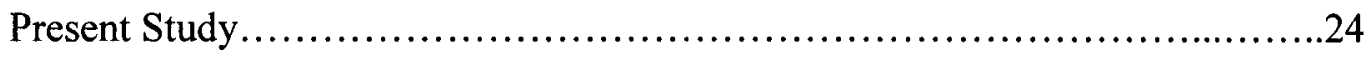

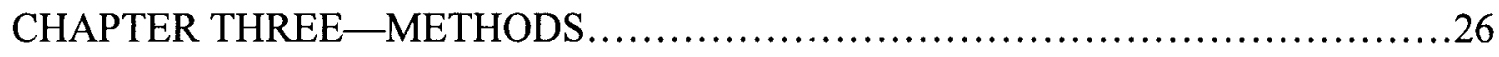

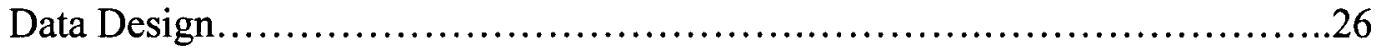

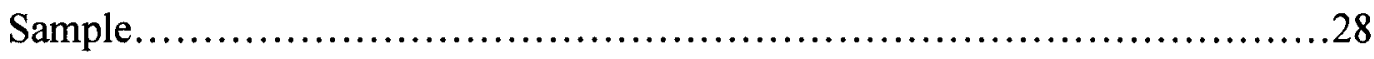




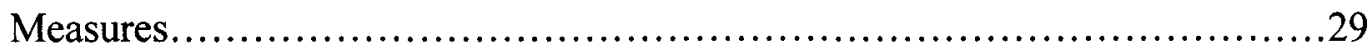

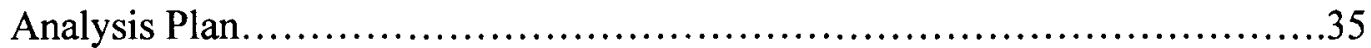

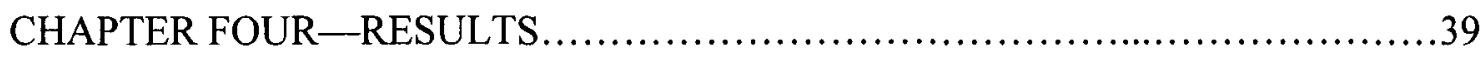

Step 1: Descriptive Statistics.............................................40

Step 2: Associations of Measures............................................42

Step 3: General School Violent Victimization.................................43

Step 4: Sex-Specific School Violent Victimization...........................47

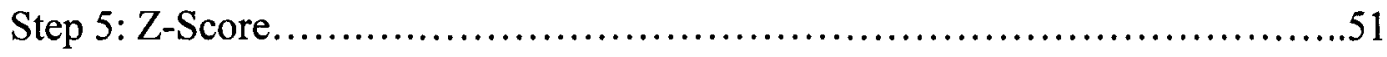

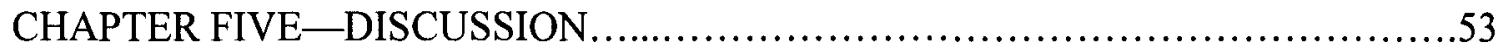

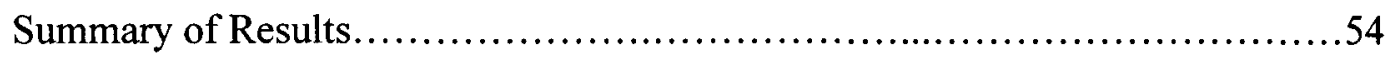

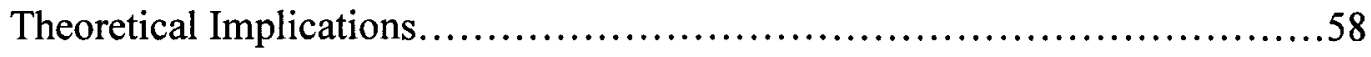

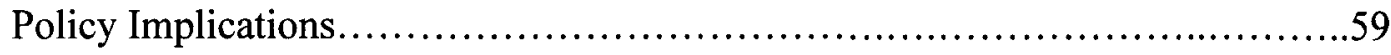

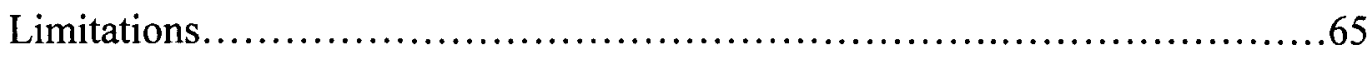

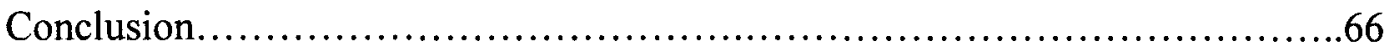

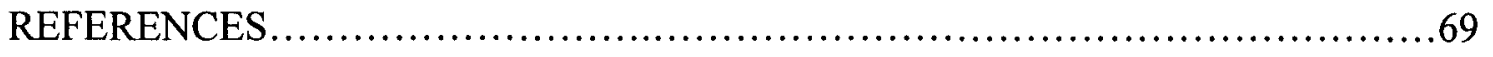

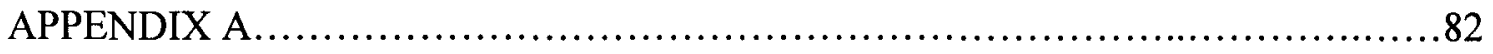

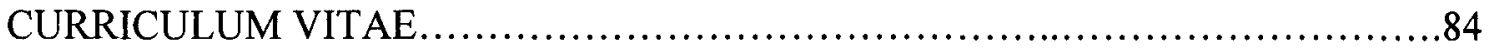




\section{LIST OF TABLES}

TABLE

PAGE

$1 \quad$ Component Matrix for Self-Control Items..............................34

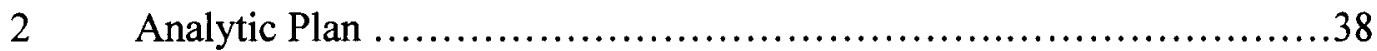

3 Descriptive Statistics................................................41

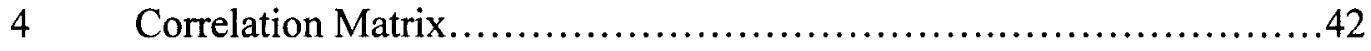

$5 \quad$ General Violent School Victimization.................................45

$6 \quad$ Violent School Victimization - Sex Differences..........................49

$7 \quad$ Z-Scores for Sex Differences in Violent School Victimization.............51 


\section{LIST OF FIGURES}

$\begin{array}{ll}\text { FIGURE } & \text { PAGE }\end{array}$

1 Scree Plot of Self-Control Measures......................................31 


\section{CHAPTER 1}

\section{STATEMENT OF PROBLEM}

Traditionally, criminological theories have separated the focuses of criminality and victimization, with criminality receiving the greater amount of attention. However, recently, a greater focus has been given to victimization research. To date, victimization research has explored the influence of demographics (i.e. age, race, and sex) and location (i.e. school, neighborhood, and home) on victimization, and the various types of victimization (theft, assault, homicide, etc.). More in-depth research focuses on the situational causal factors that are related to victimization (i.e. lack of guardianship, suitable target, and motivated offender). This research has its utility, but fails to address the social relationships that lead to higher victimization risks. This study attempts to further address this gap in research.

In the United States, millions of persons are victimized every year, and this is especially true for youths between the ages of 12 to 17 (Truman \& Planty, 2011). Truman and Planty (2011) found that the rates of violent victimization have been decreasing (rape, robbery, assault, domestic violence, and crime involving injury) from 32 per 1000 (27.9 per 1000 for assault) in the year 2002 to 22.5 per 1000 (19.4 per 1000 for assault) in 2011 (Truman \& Planty, 2011). When broken down by age, however, the findings show that victimization levels for ages 12 to 17 remain among the highest of all ages 
(Hashima \& Finkelhor, 1999). Rand (2009) examined NCVS data and found that individuals between the ages of 12 to 15 had the highest assault victimization rate (i.e. simple assault, aggravated assault, and robbery) of any age group with 35.2 per 1000 individuals.

In addition to differences across age ranges, there is evidence that suggests that there is a sex gap in victimization. Using victimization data gathered from 1973-2004, Lauritsen and Heimer, (2008) examined sex-specific victimization trends and found that the risk of nonfatal violent victimization (i.e. robbery, aggravated assault, and simple assault) has declined substantially since the 1970s for both males and females. Males are twice as likely to be victims of homicide, robbery, and aggravated assault as females (Lauritsen \& Heimer, 2008). Rand (2009) found that females had lower rates of victimization in all assault categories (simple, aggravated) at 14.3 per 1,000 as opposed to males 18.3 per 1,000 assault victimization rate.

When understanding youth victimization, it is important to acknowledge the role of location. Researchers have found that a higher rate of crime was committed against students between the ages of 12 to 18 within the school environment (including traveling to or from school), as opposed to away from school. Researchers found that students' ages 12 to 18 experienced about 828,400 violent crimes (simple assault, robbery, aggravated assault, and rape) at school, as opposed to 652,500 violent crimes away from school (Dinkes, Kemp, Baum, \& Snyder, 2010). These victimization rates were 18 crimes per 1,000 for students at school compared to 11 crimes per 1,000 for students away from school (Dinkes et al. 2010). Mayer and Furlong (2010) found that the rate of violent victimization in schools was 32 per 1,000 students - a total that is much higher than the 
Dinkes et al. (2010) results, demonstrating the variation in measurement and reporting for school victimization.

Since 1992, there has been a positive reduction in both violent victimization at and away from school, with the overall percentage of students being victimized at school dropping from 50 per 1,000 to 18 per 1,000 between the years of 1992 and 2010 (Dinkes et al., 2010). Violent victimization rates away from school dropped from 75 per 1,000 in 1992 to 11 per 1,000 in 2010. Mayer and Furlong (2010) found that while general victimization rates have decreased, they have remained higher in school than outside of school. While these findings are generally positive, victimization is occurring at a higher rate within schools as opposed to away from school (Dinkes et al., 2010; Mayer \& Furlong, 2010). This finding is particularly troublesome for educators, principles, and school staff who are charged with ensuring a safe learning environment for students because it is their responsibility to ensure a safe and orderly learning environment (Bowen \& Bowen, 1999; Burrow \& Apel, 2008; Farrington \& Ttofi, 2009) and it places them in a location that can lead to their own victimization (Dinkes et al., 2010).

Within general victimization trends, demographic indicators revealed that victimization varied by biological sex (Dinkes et al., 2010). There were differences by sex in all of the victimization categories (theft, violent victimization, and serious violent victimization). Females reported fewer instances of theft and violent victimization ( 8 per 1,000) away from schools compared to their male classmates (14 per 1,000) (Dinkes et al., 2010). Mayer and Furlong (2010) found that males (32 per 1000) had a higher victimization rate than females (25 per 1000) in regard to sexual victimization, robbery, assault, and aggravated assault. Females also reported fewer instances of violent 
altercations and weapons possession while in the school environment (Dinkes et al., 2010).

Information gathered on violent victimization in schools has revealed that victimization within the school setting operates similarly to traditional victimization. Certain groups of individuals have a higher risk of victimization than others. Victims are more likely to be male, Black, and have a lower socio-economic status (Rand, 2009). Although youth violence has declined (Dinkes et al., 2010; Mayer \& Furlong, 2010; Rand, 2009), violent school victimization has became a major concern for the public in recent years because of news portrayal of serious violence and school shootings as a serious social problem (Burns \& Crawford, 1999).

In the last 10 years, self-control has been utilized as an effective explanation for victimization, including the school environment. These studies have demonstrated selfcontrol's utility as an explanation of victimization for college students (Schreck, 1999), homicide victimization in paroled male youths (Piquero et al., 2005), drug-addicted females and street victimization (Stewart et al., 2004), and victimization within school (Schreck et al., 2002; Schreck, Stewart, \& Fisher, 2006; Stewart et al., 2011; Wilcox, Tillyer, \& Fisher, 2009). Findings from these studies suggest that those who have lower levels of self-control have higher levels of victimization than those with higher levels of self-control. This has been shown to hold true regardless of location, as well as other predictor variables.

\section{Theoretical Perspective: Self-Control Theory}

In their version of self-control theory, Gottfredson and Hirschi (1990) assume that individuals are rational decision makers. Because of this, individuals are likely to perform 
actions which they interpret as having pleasurable outcomes and avoid actions that they interpret as having painful outcomes. Individuals with lower levels of self-control weigh the benefits versus the risks associated with the action differently than those with high levels of self-control. Crime can be defined as an action of force or fraud that an individual takes part in because of the possibility of a pleasurable outcome (Gottfredson \& Hirschi, 1990). Gottfredson and Hirschi (1990, p. 14) contend that crimes are, "Shortlived, simple, easy, exciting, and immediately gratifying." Because of this, crime is most attractive to those individuals that are least able to control their urges for instant gratification (self-control).

Gottfredson and Hirschi's version of self-control theory (1990) posits that individuals with low levels of self-control are: Impulsive, prefer simple tasks, risk-takers, prefer physical activity, self-centered, and are short tempered. Individuals with low levels of self-control tend to be impulsive, meaning that they are unable to defer instant gratification (Gottfredson \& Hirschi, 1990). Risk-taking refers an individual's propensity to be adventurous instead of cautious, well-planned activities. Individuals with low selfcontrol prefer to be physically active over planning through activities (Gottfredson \& Hirschi, 1990). Individuals with low self-control tend to focus of personal gains or selfinterest over ensuring that their actions do not negatively affect others (Gottfredson \& Hirschi, 1990). Finally, Gottfredson and Hirschi (1990) argue that individuals with low levels of self-control are short-tempered, having a low threshold for frustration. Because of this low threshold for frustration, these individuals are more likely to handle conflict through physical, as opposed to, verbal resolution.

Gottfredson and Hirschi posit that self-control is relatively time stable and affects 
an individuals deference of instant gratification (Gottfredson \& Hirschi, 1990). Those with low levels of self-control are unable to resist the temptation to commit a crime whenever the opportunity arises because of the perceived outcomes (Gottfredson \& Hirschi, 1990). Criminal behavior is only one form of antisocial behavior that could be explained by self-control theory. Gottfredson and Hirschi (1990) argue that people lacking self-control, "tend to pursue immediate pleasures that are not criminal: they will tend to smoke, drink, use drugs, gamble, have children out of wedlock, and engage in illicit sex" (p. 94).

Self-control is a result of parental management practices; better parental socialization results in higher levels of self-control (Gottfredson \& Hirschi, 1990). Parental management includes parents developing a strong emotional bond or closeness to their child as well as parents monitoring the behavior of their child, analyzing the child's behavior for possible deviant actions, and the noncorporal punishment of confirmed deviant behavior. When parents fail to correct deviant behaviors, they are instilling a low-level of self-control into their child, which could result in taking part in future crime or deviant opportunities (Gottfredson \& Hirschi, 1990).

Gottfredson and Hirschi (1990) attribute differences in sex related to crime to differences in self-control, which is established through child socialization practices by age eight for children. Gottfredson and Hirschi (1990) posited that, "Supervision and socialization are not synonymous" and "boys have greater misconduct in school, where sexes are comparably supervised." This is not to say that supervision/opportunity does not reduce delinquency; supervision may well reduce overall delinquency levels, but sex differences persist in these lower levels of delinquency. Indeed, when supervision is held 
equal, differences in delinquency still exist, which suggests that self-control and social control act independently of supervision.

Self-control has been effectively utilized as an explanation for a variety of crimes and deviant behaviors. These studies find support for self-control theory on topics including deviant behaviors including: Gambling, smoking, drinking, and drug use (Piquero, Gibson, \& Tibbetts 2002; Arneklev et al., 1993; Forde \& Kennedy, 1997), bullying (Unnever, \& Cornell 2003), victimization (Nofziger, 2009; Schreck, 1999 Wilcox, Tillyer, \& Fisher, 2009; Tillyer, Fisher, \& Wilcox, 2011), assault, burglary, and robbery (Grasmick, Tittle, Bursik, \& Arneklev, 1993), and alcohol abuse (Piquero, Gibson, \& Tibbetts, 2002).

\section{Self-Control and Victimization}

While Gottfredson and Hirschi (1990) originally designed self-control theory as an explanation of crime, it also has utility in understanding victimization. Gottfredson and Hirschi (1990) state that activities that are associated with low self-control are those that bring immediate, easy, and short-term satisfaction or relief from irritation. However, with the addition of these potential positive outcomes, there is also the possibility of negative consequences to the individual's quality of life. Those with low levels of selfcontrol do not take the precautions and lack the forethought to reduce their chances of accidents and victimization. Gottfredson and Hirschi (1990) declared, "Offenders are considerably more likely than nonoffenders to be involved in most types of accidents, including house fires, auto crashes, and unwanted pregnancies. They are also considerably more likely to die at an early age" (p. 92). 
Once in a risky situation, self-control theory suggests that those with low selfcontrol increase their risk of victimization because they fail to account for the long-term negative consequences of their actions. Gottfredson and Hirschi (1990 p. 91) point out that, "People with low self-control tend to have minimal tolerance for frustration and little ability to respond to conflict through verbal rather than physical means." When looking at the six characteristics of those with low levels of self-control, it becomes clear how they could impact victimization risk. Because individuals with low self-control are impulsive, self-centered, aggressive, and prefer physical activities they do not act in a way to reduce their victimization risk. Self-control theory has been found to be a strong predictor of victimization (Baron, Ford, \& Kay, 2007; Piquero et al., 2005; Schreck, 1999; Schreck, Stewart, \& Fisher, 2006; Schreck, Wright, \& Miller, 2002; Sullivan, Wilcox, \& Ousey, 2011; Taylor, Peterson, Esbensen, \& Freng, 2007; Wilcox, Tillyer, Fisher, 2009).

\section{Present Study}

The present study seeks to address two main goals: (1) to understand which individual and social characteristics predict school violent victimization, and (2) to understand if these predictors operate in the same way across biological sex. To do this, the present study assembles several possible predictors of violent school victimization and observes how they operate for males and females. Three hypotheses are used to structure the present study:

\section{H1: Self-control, deviant peer association, age, sex, and race will affect school} violent victimization. 
H2: Self-control, deviant peer association, age, and race will affect female school violent victimization.

H3: Self-control, deviant peer association, age, and race will affect male school violent victimization.

The present study is important because it focuses on the topic of similarities and differences in victimization by biological sex, which is not a major focus of the literature. From this study, important theoretical and policy implications can be developed that address victimization effectively for males and females. By understanding what predictors are playing a role in increasing victimization, schools can adopt appropriate programming for all students. 


\section{CHAPTER 2}

\section{REVIEW OF LITERATURE}

\section{Victimization}

With increased media attention, victimization of youth has become a high-priority focus for the public (Burns \& Crawford, 1999). These crimes can either be nonviolent (theft or vandalism) or violent (assault, robbery, rape, or homicide). Over 2.2 million children are victimized each year, either while at or away from school (Dinkes et al., 2010). Victimization rates for children ages 12 to 17 are among the highest among all age groups in the U.S. when assessing levels of victimization (Truman \& Planty, 2011). Over half of their victimization occurs while they are under the care of the teachers, staff, and administrators, which run our secondary education programs (Dinkes et al., 2010).

While anyone has the opportunity to be victimized both inside and outside of the school environment, the risk is not even for every person. Researchers have shown that victimization is a nonrandom occurrence, and that certain behaviors and predispositions affect an individuals victimization risk (Fisher et al., 1998; Gover, 2004; Hannish \& Guerra, 2000; Miethe \& Meier, 1994; Mustaine \& Tewksbury, 1998; Schreck et al., 2004). Research has also found that victims of crime have remarkably similar traits to those who are committing crimes (Lauritsen et al., 2008; Mustaine \& Tewksbury, 1998; Woodward \& Fergusson, 2000). Due to the assertion that victims share many traits with offenders, it is plausible that a criminological theory like self-control theory could be utilized to understand victimization rates in a variety of circumstances in order to 
understand whether the victimization is or is not a random occurrence. In the following sections, literature on individual level predictors (self-control and peer association) will be used to outline the present study.

\section{Parental Management}

Gottfredson and Hirschi (1990) attribute the formation of self-control to management functions carried out by parents. Gottfredson and Hirschi specifically state "the major cause of low self-control thus appears to be ineffective child-rearing" (p. 97). In order to effectively instill self-control within a child, parents should possess a warm relationship with their child, monitor the child's behavior, analyze the child's behavior for instances of deviance, and correct them using noncorporal punishment (Gottfredson \& Hirschi, 1990). The majority of this self-control formation takes place within the formative years of eight to ten years of age (Gottfredson \& Hirschi, 1990).

Several studies have examined the relationship between parental management and self-control, finding consistent support for the importance of appropriate parenting practices for higher levels of self-control. These studies tend to focus on the individual steps attributed to effective parenting: (1) monitoring, (2) detection and analysis, and (3) punishment of deviant actions or activities. Parental monitoring has been shown by a number of researchers to impact self-control levels in children (Hay, 2001; Pratt, Turner, \& Piquero, 2004; Nofziger, 2008; Unnever, Cullen, \& Pratt, 2003).

In addition to parental monitoring, Gottfredson and Hirschi (1990) emphasize the importance of noncorporal and consistent punishment. Several researchers have found that the utilization of consistent, noncorporal punishment can effectively increase children's self-control levels (Gibbs \& Giever, 1995; Gibbs, Giever, \& Martin 1998; 
Nofziger, 2008; Unnever, Cullen, \& Pratt 2003). Hay (2001) examined the role that parental monitoring and discipline on self-control finding that proper parenting improves self-control levels. Additionally, Hay (2001) found that non-corporal and fair punishments increased self-control while physical punishment reduced self-control.

Proper parenting practices are integral in the formation of self-control within a child; Proper parenting has the potential to provide an example for self-control in order to effectively instill this quality in children. Nofziger (2008) found that the self-control levels of the mother directly affected how the mother completed parental management strategies on their child. In turn, this variation in parental management affected the child's level of self-control. This means that parents with higher levels of self-control are more apt to take the time to perform parental management functions effectively.

Due to the lower levels of self-control that are instilled by poor parental management practices, these individuals are far more likely to become involved in criminal and deviant behavior (Gottfredson \& Hirschi, 1990). Researchers have linked low levels of self-control to a variety of deviant behaviors such as: Gambling, smoking, drinking, and illicit drug use (Piquero, Gibson, \& Tibbetts 2002; Arneklev et al., 1993; Forde \& Kennedy, 1997), bullying (Unnever, \& Cornell 2003), assault, burglary, and robbery (Grasmick, Tittle, Bursik, \& Arneklev, 1993), victimization (Baron, Ford, \& Kay, 2007; Piquero et al., 2005; Schreck, 1999; Schreck, Stewart, \& Fisher, 2006; Schreck, Wright, \& Miller, 2002; Sullivan, Wilcox, \& Ousey, 2011; Taylor, Peterson, Esbensen, \& Freng, 2007; Wilcox, Tillyer, Fisher, 2009), and alcohol abuse (Piquero, Gibson, \& Tibbetts, 2002). Pratt and Cullen (2000), found that self-control was consistently linked 
to causality as one of the strongest indicators of crime, as it was for any of the major criminological theories, thus solidifying its importance as a determinant of crime.

Evans et al. (1997) utilized self-control theory to look at various types of crime, imprudent behavior, negative life outcomes, and social consequences. Researchers found that low self-control translates into a variety of negative consequences such as: Poor relationships with family and friends, low church attendance, poor educational attainment, low job outlooks, and poor relationship opportunities. Individuals with low levels of selfcontrol were also more likely to have criminal acquaintances (Evans et al. 1997). Building upon these findings, Piquero and colleagues (2005) examined the relationship between low self-control, violent offending, and homicide victimization, finding that both violent offending and homicide victimization are a result of low levels of self-control. Individuals with low levels of self-control place themselves at a greater risk of victimization because of the lives that they live, becoming involved in violent offending because of its perceived benefits leads to being at a greater risk for homicide victimization.

\section{Sex Differences in Parental Management}

When observing self-control within the context of victimization, it is important to acknowledge differences in self-control levels by sex. The literature regarding the

relationship between sex, self-control, and crime is relatively small when compared to the massive quantities of literature on self-control in general. Gottfredson and Hirschi (1990) argued that the same factors that lead to criminality are present in both males and females; differences in criminality are attributed to differences in parental socialization practices for men and women. The combination of parental attachment, supervision, 
observation, and punishment of deviant activities is what acts to build higher levels of self-control. Research generally supports Gottfredson and Hirschi's (1990) assumptions that parental management activities influence levels of self-control (Gibbs, Giever, \& Martin, 1998; Hay, 2001; Hay \& Forrest, 2006; Unnever, Cullen, \& Pratt, 2003; Vazsonyi \& Bellistion, 2007).

Other researchers have looked at all of the parental management components, which is in line with the reasoning of Gottfredson and Hirschi, and found that self-control is the result of all of the parental management components and not just supervision or punishment. Gibbs, Giever, and Martin (1998) found that parental socialization indirectly effects delinquency through self-control. In addition, researchers found that parental socialization has a direct effect on self-control levels. In turn, self-control has a direct effect on delinquency for males and females. This assertion remained significant across sex lines, where researchers found only a small variation in parental socialization across sexes.

Hay and Forrest (2006) were able to elaborate on the prior research by measuring the effect of parental socialization over time. Researchers showed that parents who did not have good relationships with their children, did not monitor them, and did not punish them appropriately were more likely to have children with lower levels of self-control. LaGrange and Silverman (1999) found that females have higher levels of selfcontrol and report higher levels of parental/adult supervision than their male counterparts. Elaborating on those results, Higgins (2004) provides the first clear examination of the role of parental management and self-control, pertaining specifically to sex. Findings indicate that parenting practices for males and females are significantly different and 
because of this, sex differences in levels of self-control appear. Further, the results showed that male levels of delinquency were higher than female levels and that a similar causal model is used across sex lines in understanding the formation of self-control. Taken together, this information states that self-control is formed similarly across sexes and those differences in parental management lead to lower levels of self-control for males and higher levels of self-control for females.

\section{Self-Control Across Sex Lines}

Gottfredson and Hirschi (1990), posit that females are less likely to commit crimes/deviant acts because they have higher levels of self-control compared to their male counterparts. They reason that sex differences in crime and delinquency are established early in life and continue throughout the life course. Numerous researchers have found that females have higher levels of self-control than males (Arneklev et al., 1993; Burton et al., 1998; Chapple \& Johnson, 2007; Gibbs \& Giever, 1995; Higgins \& Tewksbury, 2006; Hope \& Chapple, 2005; LaGrange \& Silverman, 1999; Longshore, 1998; Mason \& Windle, 2002; Nakhaie, Silverman, \& LaGrange, 2000; Tittle et al., 2003; Turner \& Piquero, 2002; Winfree et al., 2006; Wood, Pfefferbaum, \& Arneklev, 1993).

Although research has shown that males generally have lower levels of self-control than females, there are still several questions that need to be answered. Researchers have found that self-control measures may operate very differently for males and females. For instance, items from the Grasmick et al. (1993) scale may be perceived differently for males and females, potentially distorting the overall self-control score (Gibson, Ward, Wright, Beaver, \& Delisi, 2010; Higgins, 2007; Piquero, McIntosh, \& Hickman, 2000). 
Higgins and Tewksbury (2006) found that self-control has predictive power for males and females in both acts of force (beating up others and taking others' things) and fraud (theft, automotive theft, and vandalism). However, Higgins and Tewksbury noted that low self-control was better able to predict male delinquency over female delinquency. This finding suggests that there are more components that need to be considered in order to accurately measure self-control across sex lines. Delinquency was also significantly different between sexes with females having a statistically significantly lower rate of delinquency then males. Most importantly, it was found that self-control was not equally distributed across sex; females had a much higher level of self-control that resulted in part from higher levels of parental monitoring and management.

In contrast to the findings of Higgins and Tewksbury (2006), other researchers have found that self-control is still an adequate measure across sex lines. Gibson, Ward, Wright, Beaver, and Delisi (2010), tested sex and self-control in a college sample to determine if there are self-control differences between sexes in delinquency. They found that self-control adequately explains differences in delinquency instances according to biological sex. Gibson and colleagues (2010) examined sex differences in self-control in order to understand if self-control was a sex-neutral theory. Using factor analysis, researchers analyzed how the Grasmick et al. (1993) scale was operating for males and females. While there were several items that were biased toward females, the scale was still able to measure self-control across sex. When the biased items were removed, females still had a significantly higher self-control score than the male sample (Gibson et al., 2010).

Tittle, Ward, and Grasmick (2003) addressed the issue of sex differences in self- 
control and crime and delinquency measures. Sex and age were found to be significant indicators of crime and deviance (Tittle et al., 2003). The results also show that all three measures of self-control were significant in understanding crime and deviance. Perhaps the most important of their findings is that the behavioral measures of self-control reduced the effect of sex and age to nonsignificance (Tittle et al., 2003). This information shows that self-control theory is an effective measure of crime and deviance across sex and age, thus proving its utility as a universal indicator.

\section{Self-Control and Victimization}

While Gottfredson and Hirschi (1990) originally designed self-control theory to understand offending, it also has utility in understanding victimization. There are several studies that show evidence of a relationship between self-control and victimization (Baron, Ford, \& Kay, 2007; Piquero et al., 2005; Schreck, 1999; Schreck, Stewart, \& Fisher, 2006; Schreck, Wright, \& Miller, 2002; Sullivan, Wilcox, \& Ousey, 2011; Taylor, Peterson, Esbensen, \& Freng, 2007; Wilcox, Tillyer, Fisher, 2009). Self-control has also been shown to be an effective explanation for victimization in high school students (Nofziger, 2009; Schreck, Wright, \& Miller, 2002; Wilcox et al., 2009), college students (Schreck, 1999), homeless male street youths (Baron, Ford, \& May, 2007), and female offenders even after controlling for personal criminal behavior and demographics (Stewart, Elifson, \& Sterk, 2004).

Schreck (1999) used an interpretation of Gottfredson and Hirschi's (1990) six personality characteristics of individuals with low levels of self-control to relate selfcontrol theory to victimization. Those with low self-control seek immediate gratification compared to individuals with high self-control who are more inclined to defer rewards or 
seek immediate gratification. Those with low self-control are more likely to seize opportunities to seek pleasure without forethought of the consequences or potential dangers involved in their behavior. People with low self-control tend to be drawn to exciting, risky activities (Schreck, 1999). This need for excitement places individuals in high-risk situations that increase the risk of victimization. Individuals with low levels of low self-control prefer physical activities to those that are planned out or that require more mental effort. This preference for physical over cognitive reasoning puts the individual at risk for physical altercations because of their limited ability to utilize other problem solving skillsets (Schreck, 1999).

Building on previous work, Schreck and colleagues (2002) used a $9^{\text {th }}$ through $11^{\text {th }}$ grade sample to examine the relationship between low self-control and school violent victimization. Self-control had a significant relationship on violent victimization, even when controlling for a variety of other predictors, including risky lifestyles and school bonds. Further, self-control had the largest regression scores of any of the variables on violent victimization among high school students. These findings show the viability of self-control in predicting victimization in both the school atmosphere and the home environment.

Schreck et al. (2006) used longitudinal data on victimization and self-control to determine the relationship and stability of the relationship between these two concepts. Low self-control was found to be associated with victimization over time, even when past victimization, delinquency, social bonds, and deviant peer association are controlled for. Individuals possessing low self-control who experience victimization possess a 
significantly greater amount of longitudinal stability in their deviant acts and association with deviant peers than those with greater self-control.

In addition to the work of Schreck, other researchers have used self-control theory to study victimization within the context of school environment. Taylor and colleagues (2007) found that impulsivity and risk-taking attitudes were significantly and positively related to violent victimization. Parental supervision was the only other variable that reached significance within the model; social bond measures were rendered nonsignificant. Building on this finding, Wilcox et al. (2009) found that self-control was a strong indicator of theft, sexual, and assault victimizations within middle school. Selfcontrol was shown to operate well across sexes and to remain significant even when including peer delinquency, social bonding, and demographic indicators. This is similar to Tillyer et al. (2011) who found that self-control was an effective indicator of middle school student victimization, even when accounting for a variety of additional variables. The limitation of these studies, however, lies in their cross-sectional sampling method. This design prevents the study from creating a predictive connection between self-control and victimization within school.

Building upon prior research victimization and self-control research, researchers utilized longitudinal data to understand victimization over time (Higgins, Jennings, Tewksbury, \& Gibson, 2009). Individuals with low levels of self-control were found to fall into one of two victimization trajectories: (1) low rate declining or (2) high rate persistent. These findings show that low levels of self-control can impact an individual's victimization risk over time-not necessarily a single, isolated event. 
One study that did utilize a longitudinal focus was performed by Sullivan et al. (2011). Researchers performed a trajectory analysis on juvenile victimization in order to understand the differentiation of school victimization (i.e. physical assault, robbery, theft without contact, threat involving a gun, and threat involving a weapon other than a gun) trends over time (Sullivan et al., 2011). Utilizing social bond, self-control, and peer association, researchers found that students with the highest average victimization levels had higher levels of self-reported offending, self-control, deviant peers, and illegal opportunities but lower levels of school bonds. This indicates that those that are victimized are also involved in criminal endeavors, which is consistent with prior victimization research. However, this study did not look at differences along biological sex. The present study seeks to address this gap in the literature.

\section{Deviant Peer Association and Self-Control}

When discussing Gottfredson and Hirschi's (1990) version of self-control theory, it is necessary to include deviant peer associations (Pratt \& Cullen, 2000). Pratt and Cullen (2000) argue that a self-control study that fails to include peer association risks being misspecified. Deviant peer associations is a concept within Akers' (1998) social learning theory that posits that increased participation and identification with peer groups that display or are permissive of illegal activities will lead to the adoption and continuation of those activities by the subject.

Akers' (1998) social learning theory is comprised of four components: (1) differential associations, (2) definitions of behavior, (3) imitation, and (4) reinforcement. Social learning theory operates through a process where a behavior-either conforming or nonconforming - is learned and adopted or discontinued based on reactions from 
social structure, social interaction, and situation. An individual is much more likely to perform deviant activities when differentially associating with others who commit criminal behavior and/or view deviant behavior favorable.

Differential association refers to the relationships and interactions that an individual has with both their primary groups and secondary groups who engage in and support certain types of behavior which can be either illegal or legal in nature.

Definitions refer to the attitudes, values, and behaviors that help an individual to decide whether an act is right or wrong (Akers, 1998). Differential reinforcement is the anticipation of rewards or punishments for performing a certain action; these reinforcements can be psychological, material, or social (group approval). Social and nonsocial reinforcers and punishers affect how frequently, if at all, future criminal acts will occur. Lastly, imitation involves engaging in a behavior after observing others, possibly from a peer group who performs those behaviors. These concepts affect an individual's learning of prosocial or antisocial models of behavior.

Gottfredson and Hirschi (1990) view the peer effect on delinquency as the result of an underlying trait, specifically low self-control. Individuals with low levels of selfcontrol tend to dislike areas or institutions that require constraints on behavior. For this reason these individuals are attracted to same sex peer groups; however, their impulsiveness, untrustworthiness, and self-centeredness are not conducive to the growth of peer bonds. It is because of this inability to make close peer relationships that individuals with low self-control end up with other individuals who also lack self-control. Thus the individuals in the group, as well as the group itself, will be deviant. Akers (1998) on the other hand, posits that association with a deviant peer group can lead to 
learning illegal actions through imitation and acceptance of definitions that are nonconforming to acceptable societal definitions. This, in turn, can lead to the initiation of an illegal behavior or action that will receive positive reinforcement from the deviant peer group, thus ensuring its continuation.

Although each of these components has been shown to be an effective measure of social learning, Pratt and colleagues (2010) found that differential association is by far the most commonly used measure of social learning in the literature, and also has the highest effect size of any social learning variable. Peer association is used more than any other variable to explain social learning theory, both in studies focused on social learning, as well as a control variable for other criminogenic theories. Pratt and colleagues (2010) found that peer association consistently had a strong effect size, and rivaled the explanatory power of self-control theory when they were used in conjunction with one another.

Numerous researchers have addressed the issue of peer association within selfcontrol and shown that it is an important contributor to understanding crime and deviance (Evans et al., 1997; Pratt \& Cullen, 2000). Several researchers have further shown that the introduction of self-control into a model designed to measure peer association fails to eliminate the effect of deviant peers (Baron, 2004; Burton et al., 1998; Evans et al., 1997) and to be a more robust indicator for most forms of crime than low self-control (Pratt \& Cullen, 2000; Pratt et al., 2009; Tittle et al., 2003). Research indicates that individuals with lower levels of self-control self-select into deviant peer groups in the real world (Chapple, 2005; Evans et al., 1997; Longshore, Chang, Hsieh, \& Messina, 2004; Mason \& Windle, 2002). 
Indeed, the effects of self-control and deviant peer associations both play an important role in crime and victimization, but how they interact has received little academic focus, either in the crime or victimization literature. Tillyer et al. (2011) found that deviant peer associations increased violent victimization risk even when accounting for self-control. Schreck, Fisher, and Miller (2004) examined the effect of peer networks on violent victimization and found that a delinquent peer group increased the risk of victimization for an individual, while the opposite held true for conventional peer groups.

Further, they found that members who were centralized in a deviant peer group structure were more likely to be victimized than peripheral members. McGloin and Shermer (2009) examined this relationship using peer network structure in addition to self-control. Researchers found that self-control and peer association variables have an independent affect on crime risks. In addition to this, however, McGloin and Shermer (2009) found that centrality within a deviant peer group increased the effect of deviant peers on future delinquency, even when accounting for self-control levels. Stated another way, self-control dictates selection into deviant peer networks, peer association still holds additional criminogenic importance. It was also found that self-control impacts more dimensions than just association with deviant peers; low self-control increases peer involvement, whether it is deviant or not. The findings of this study demonstrate the complex and interrelated relationship between peer association and self-control, and why they should both be observed. Peer networks clearly play a role in victimization risk and thus must be included in the present analysis.

By including deviant peer association measures into our investigation of violent school victimization, we are challenging the robustness of the self-control measure by 
introducing a competing, and equally powerful indicator of delinquency in understanding violent school victimization in 12- to 18 -year old adolescents. The following sections will introduce the hypotheses for the present study and examine the predictive ability of these criminological theories on violent school victimization across biological sex.

\section{Present Study}

The present study has two main purposes: (1) to understand possible predictors of violent school victimization and (2) to observe how they operate for males and females. To examine school violent victimization items measuring self-control, deviant peer associations, sex, age, and race will be utilized in order to understand possible predictors of violent school victimization. In addition to observing the entire sample, an analysis will be performed examining the predictive power of these variables on males and females separately. Three hypotheses will be utilized in the present study:

H1: Self-control, deviant peer association, age, sex, and race will affect school violent victimization.

H2: Self-control, deviant peer association, age, and race will affect female school violent victimization.

H3: Self-control, deviant peer association, age, and race will affect male school violent victimization.

The present study expects to find that the predictors of victimization will differ between males and females. This study will yield policy implications for schools that are experiencing violent victimization. The results of the present study will be able to inform educators and school administrators of the possible predictors of victimization within the school atmosphere. Knowledge of which predictors are effective and ineffective will 
allow for policies in the school to be appropriately adopted or adjusted, reducing the instances of victimization in school. Ultimately, the findings from the present study could lead to the adoption of new policies that enhance student safety within the school environment. 


\section{CHAPTER 3}

\section{METHODS}

This study has two main purposes. First, this study will examine school violent victimization using measures of self-control, deviant peer association, and demographic factors to understand the possible predictors of violent school victimization on the general sample. Second, it will delve deeper into the school violent victimization dependent variable and examine the effects of self-control, deviant peer association, and demographic factors by sex. This will allow the results to show how each of the independent variables relate to the dependent variable and the strength of their explanatory power for males and females separately. The present study is important because it sheds light on the differences or similarities of possible predictors of victimization by sex. This study will yield policy implications for schools that are experiencing violent victimization.

\section{Data Design}

Data for the present analysis was drawn from an evaluation of the Community Works Program from the Inter-University Consortium for Political and Social Research at the University of Michigan (Esbensen, 2011). The Community Works program is a law-related school initiative that targets $6^{\text {th }}$ through $9^{\text {th }}$ grade students. To gather the data for the evaluation, researchers utilized a group-administered, self-report survey method, for which students individually answered questions that were presented by a researcher. 
The Denver Youth Survey (Huizinga, Esbensen, \& Weiher, 1991) was the primary source of the scales used for measurement.

The sampling method involved multiple selection criteria to ensure that the components and effects of the Community Works program were being accurately captured (Esbensen, 2011). Program information indicated that it was used or adopted in 250 schools, which did not account for the level of implementation of the program (Esbensen, 2011). Only 18 of the 250 schools indicated that they met the criteria for inclusion in the evaluation (Esbensen, 2011). These criteria included (Esbensen, 2011):

- Program was taught in its entirety;

- Adequate classroom coverage to allow for control and treatment groups as well as being cost-effective for the travel of the investigators;

- Willing to withhold the program to create control groups; and

- Adhering to the evaluation design.

Fifteen schools from nine cities in four states were found to have both properly initiated the program and interest in evaluation participation (Esbensen, 2011). Nine schools from Arizona, one in New Mexico, two in Massachusetts, and three in South Carolina were included in the sample population intentionally due to the higher concentration in the southwestern states, including Arizona (Esbensen, 2011). The results of this study are not generalizeable, due to the higher than average concentration in the southwest U.S.; this concentration in the southwest was a result of higher program implementation in this locality (Esbensen, 2011). Within the school, program and nonprogram classes both had similar demographics to the rest of the school (Esbensen, 2011). 
Participating $6^{\text {th }}$ through $9^{\text {th }}$ grade classes were paired based on their grade and subject. Random assignment was not possible because only some of the teachers had the training necessary to implement the Community Works program and fulfill the evaluation criteria (Esbensen, 2011). Classes are paired by grade and subject, so that program exposure and control groups are the same. In all, 48 classrooms were in the treatment group and 49 were in the control group. The evaluation contained three steps of data collection: (1) pretest, (2) a 6-month posttest, and (3) a 6-month follow-up to the posttest. The present analysis only utilizes information from the first wave of data-with the exception of the school violent victimization variable - which comes from the wave twoposttest information.

\section{Sample}

The sample for the present study came from the program and control classrooms from wave one and wave two (just violent school victimization) of the Community Works program. ${ }^{1}$ Overall, program and non-program students $(n=2,353)$ were asked to participate in the evaluation of the Community Works program. Seventy-two percent $(72 \%)$ of parental consent letters were returned with an approval rate $(n=1,686)$, while $12 \%$ were returned as refusal $(n=290)$ and $16 \%$ were not returned at all $(n=377)$. This left the sample size at $n=1,686$. The sample was $46 \%$ male and $54 \%$ female. With regard to race, white students made up $36.3 \%$ of the sample population, with the remaining $63.7 \%$ of the sample being minority students. Of this minority student population, a majority consists of Hispanic students (40\%), with Black students (10.2\%), and other $(13.5 \%)$ making up the rest of the sample population.

\footnotetext{
1 Although the information comes from the pre and posttest evaluation data, a control for a possible program effect was not included in the analysis. A process evaluation found that program implementation was not uniform, thus preventing an estimation of a program effect (Esbensen, 2009).
} 


\section{Measures}

School Violent Victimization. The Departments of Education and Justice define school violent victimization as simple assault, threats, aggravated assault, and robbery (Dinkes et al., 2010). The item that measures in-school violent victimization was school "been attacked or threatened at school." This question has been utilized as an indicator of school victimization successfully in prior research (Esbensen \& Carson, 2009; Melde \& Esbensen, 2009). The measure of school violent victimization consisted of one item. Responses were coded as $1=$ yes and $0=$ no. Although this measure does not capture the frequency or specific type of victimization, it does correctly capture the occurrence of a victimization event that is violent in nature to an individual in the school environment. Because multiple waves of the data are being utilized, it is important to assess the possibility of missing data due to sample attrition. The wave one measurement for school violent victimization had 1,589 responses, and the second wave had 1,470 responses-for an overall attrition rate of $9.25 \%$.

Self-Control. The self-control measure used in the present study consisted of 16 items representing four subscales from the Grasmick et al. (1993) measure of self-control. Using only some of the responses or subscales has been a generally acceptable within prior literature (Unnever \& Cornell, 2003). The four subscales of the Grasmick et al. (1993) self-control questionnaire were: (1) impulsivity, (2) risk-taking, (3) aggression, and (4) self-centeredness. These subscales must be combined into a single, unidimensional item to be in line with the theoretical basis provided by Gottfredson and Hirschi (1990). This is because each of these traits touches on a single, latent trait that explains victimization risk (Arneklev, Grasmick, \& Bursik, 1999). 
Multiple variables are often condensed into a much smaller number of factors in an attempt to both simplify the data and to measure an underlying concept; one that cannot be directly observed within the data (Field, 2003). For any analysis to be successful, the measures used must be constructed correctly in order to ensure that they are both reliable and valid (Field, 2003). Checking for unidimensionality (items combined into a single measure that are all highly correlated) ensures that individual items that are combined to form a scale are in fact measuring a singular concept or idea, instead of a variety of different concepts. To test for unidimensionality of a scale, a factor analysis is performed (Field, 2003).

Factor analysis allows for a determination of whether items that are selected to represent a single, underlying concept are in fact measuring a single concept. This is done by statistically demonstrating the relationship of one variable to the rest of the group of variables in order to determine if there is a strong relationship. Factor analysis is based on the correlation of the items to be included into a single item or scale (Field, 2003). Because a factor analysis is based on correlations between items to be combined, a large sample size is required due to the fact that correlations require a large sample size in order to stabilize (Field, 2003; Kim \& Mueller, 1978). Researchers suggest that a sample of 1,000 participants will provide excellent results in factor analysis, while a minimum of 10 observations is necessary to avoid computational difficulties (Comrey \& Lee, 1992; Field, 2003).

To perform a factor analysis on the self-control measure, eigenvalues for each scale variable must be examined. ${ }^{2}$ These eigenvalues can indicate the importance of that

${ }^{2}$ The eigenvalue for a given factor measures the variance, which is accounted for by that factor. A low eigenvalue suggests that the factor adds little to the explanation of variances in the variables (Field, 2003). 
measure to the subscale. To assess if the eigenvalue is large enough to be included, a scree plot is utilized. A scree plot places eigenvalues on a Y-axis and the list of given factors on the $\mathrm{X}$-axis. The point that corresponds to the largest dip in the plot line is considered to be the determination for important factors (Kim \& Mueller, 1978). Figure 1 shows the results of the scree plot for the self-control factor analysis. Looking at the scree plot, the largest dip in the line is located between the first and second component. The eigenvalue for component one is 4.62 , with the next highest value being 1.48 for component two. Values up to component four all remain above 1.22.

Figure 1: Scree Plot of Self-Control Measures

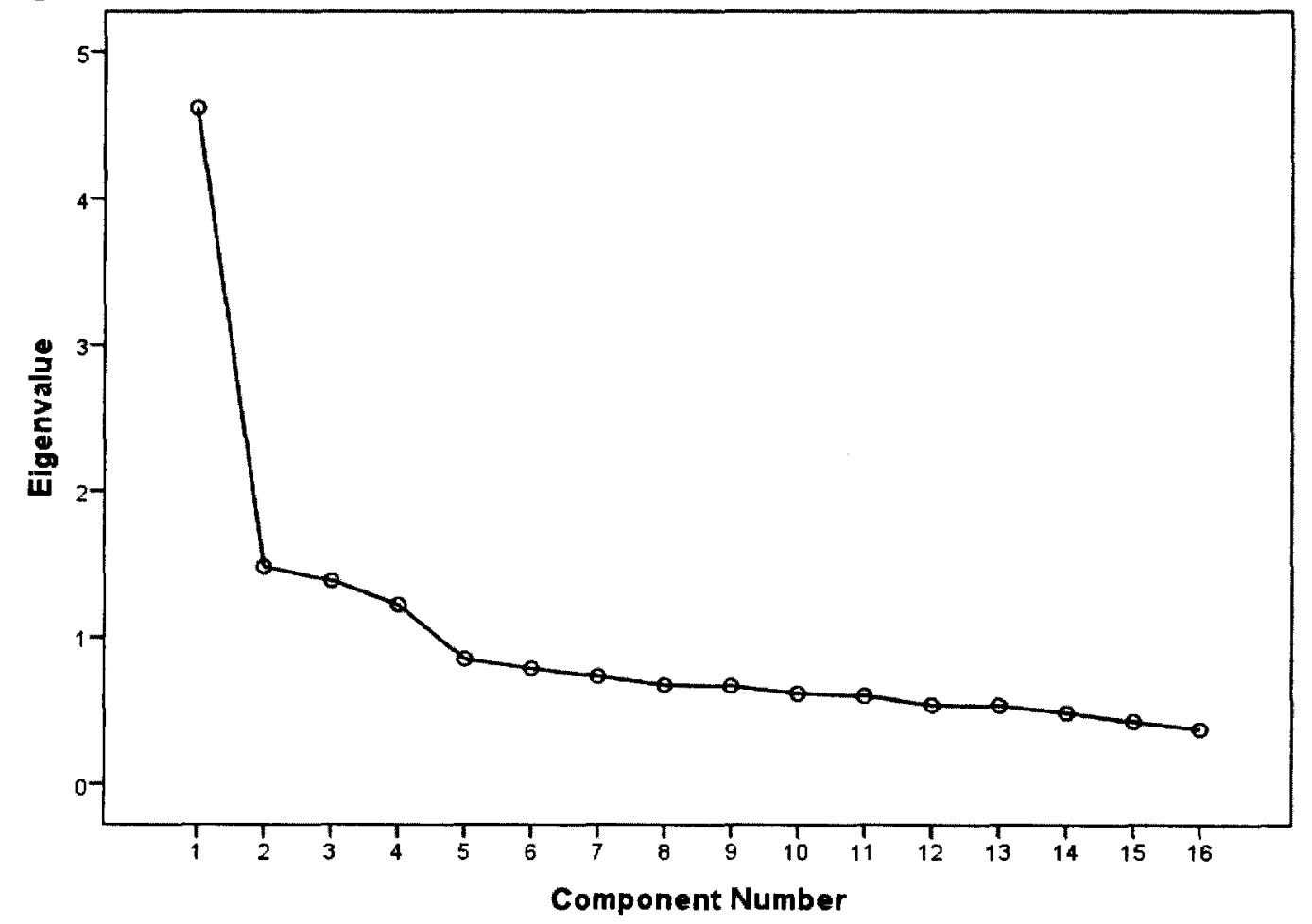

In addition to using a scree plot to determine what items to retain in the factor analysis, factor loadings are also recommended (Field, 2003). Four values were found in the scree plot with an eigenvalue over one, suggesting that more than one component was 
present in the results. These four factors will be extracted and examined in relation to each of the individual items. Once the factors are extracted, factor loadings are assigned allowing for the analysis to see which items are correlated to which factor (Field, 2003).

It is important to perform some method of rotation when performing factor loading in order to prevent most items from loading on the early factors, and usually, of having many items load substantially on more than one factor. Rotation allows items to load strongly on one variable and much more weakly on others in order to simplify the relationship (Kim \& Mueller, 1978). Varimax rotation with Kaiser normalization was utilized in the present study because it allows for the components to be treated independently while rotating the axes for the factors to allow for each factor to load optimally on only one factor (Field, 2003). ${ }^{3}$ This type of rotation is considered orthogonal, meaning that factors are relocated on the plane while retaining 90-degree angles to each other after rotation, thus keeping the variables unrelated to each other and maximizing their independence (Field, 2003).

Factor loadings greater than 0.40 indicate a high factor loading for each item (Field, 2003). Table 1 shows the results of the rotation. Each of the four factors was found to have to correct items loading to them, indicating that the scale is operating in accordance to prior literature. All of the factor loadings for the four factors were above the 0.40 minimum acceptable threshold. Only one item, "I often act on the spur of the moment without stopping to think," scored below a factor loading score of 0.50 . This may be because this question could also be addressing a portion of risk-taking. Looking

\footnotetext{
${ }^{3}$ Kaiser normalization is the process of rescaling rows of loadings to have a norm 1 before a rotation is performed and then unscaled after rotation (Field, 2003).
} 
at the questions that were grouped in Table 1 , it is clear that the each of the items share a single theme: impulsivity, anger, self-centeredness, and risk-taking.

Having completed the factor analysis, the self-control scale was then created by adding the values of each item into a single item representing self-control. The 16 items from Table 1 were combined to form an additive self-control scale going from 16 (high self-control) to 80 (low self-control). The Cronbach's alpha for the 16 items was 0.80 , indicating a high internal consistency among the items (Chen \& Krauss, 2004). ${ }^{4}$ This score indicates that that the items that the items group well together and measure the same concept of self-control. A five-point Likert-type scale was used to capture the respondent's answers to the items $(1=$ strongly disagree to $5=$ strongly agree $)$. Higher scores on the scale indicated lower levels of self-control.

\footnotetext{
${ }^{4}$ Cronbach's alpha is a measure of internal consistency for scale items. Items that receive a score over 0.70 are considered to have a high consistency in measuring the same concept (Chen \& Krauss, 2004).
} 
Component Component Component Component

\begin{tabular}{l}
\hline 1. I often act on the spur of the moment without stopping to think \\
2. I don't devote much thought and effort to preparing for the future \\
3.I often do whatever brings me pleasure here and now, even at the cost of some distant \\
goal \\
4. I'm more concerned with what happens to me in the short run than in the long run \\
5. I like to test myself every now and then by doing something a little risky \\
6. Sometimes I will take a risk just for the fun of it \\
7. I sometimes find it exciting to do things for which I might get in trouble \\
8. Excitement and adventure are more important to me than security \\
\hline
\end{tabular}

9. I lose my temper pretty easily I am angry

11. When I'm really angry at people I feel more like hurting them than talking to them about why I am angry

12. When I have a serious disagreement with someone, it's usually hard for me to talk calmly about it without getting upset

13. I try to look out for myself first, even if it mean making things difficult for other people

14. I'm not very sympathetic to other people when they are having problems

15. If things I do upset people, it's their problem not mine

16. I will try to get the thing I want even when I know it's causing problems or other people 
Deviant Peer Association. Two items were used to capture the concept of deviant peer association from this data. The first measure was whether the respondents' peer group participated in illegal activities. Specifically, the measure was, "Do people in your group actually do illegal things together?" and "Is doing illegal things accepted or ok in your group?" While this scale does not address frequency or magnitude of deviant peers associations, it does correctly capture the association effect. Other researchers have been able to utilize this form of deviant peer associations' measurement in the past with success (Melde \& Esbensen, 2011). Each of the respondents' responses were coded as 1 $=$ yes and $0=$ no. These items were then combined into a single scale for peer association that ranges from 0 to 2, with a higher score representing more deviant peer associations. This single measure was shown to have a high internal consistency using the Kuder-Richardson -20 formula (KR-20) $(\mathrm{KR}-20=0.76) .{ }^{5}$

Demographic Control Measures. The survey instrument gathered various demographic measures to understand the characteristics of the sample. The demographic control measures for this study include the following: biological sex, age, and race. Biological $\operatorname{sex}(1=$ males, $0=$ females $)$ and race $(1=$ white, $0=$ non-white $)$ where dummy coded. Respondents' age ranged from 10 to 16 in the Community Works program; it was consolidated into a four-point categorical measure $(1=$ under $12,2=12,3=13$, and $4=$ over 13). Age is coded as a categorical variable instead of continuous variable due to the initial coding by the primary researcher (Esbensen, 2011).

\section{Analysis Plan}

The analytic plan for the present study takes place in five steps, which are

\footnotetext{
${ }^{5}$ The Kuder-Richardson - $20(\mathrm{KR}-20)$ formula is an internal consistency measurement similar to Cronbach's alpha, only for dichotomous variables. A value above 0.70 is desirable and indicates that the items in the created scale are measuring the same concept (Thompson, 2010).
} 
presented in Table 2. In step 1, the characteristics of the data will be examined to ensure that it does not violate any normality assumptions, as well as to describe the general trends of self-control and violent victimization in the sample, as well as the demonstration characteristics of the sample in regard to sex, race, and age. If the data used in the scale is not normally distributed, it will violate the assumptions of normality and therefore the data will be violated (Kim, \& Mueller, 1978). Two measures of distribution are skewness - a pile-up of information at one end of a distribution, and kurtosis, the pointedness of a distribution - are used to check for normality within a distribution (Field, 2003). The closer the scores are to zero, the more normal the data distribution, with values over two indicating a problematic distribution (Field, 2003). This allows us to understand the nature of the information and its distribution, thus allowing for the proper choice of statistical technique to utilize.

Step 2 of this analysis will address the association of measures used in the present study. A correlation analysis will allow the present study to show the strength of each of the variables' relationships to each other and the direction of each relationship. Knowing these relationships will begin to inform the present study on the complex relationships associated with violent school victimization.

Step 3 of the analysis will address hypothesis one using logistic regression to understand the predictive ability of the independent variables on violent victimization. Regression is a statistical technique that was used for determining the correlates of a dependent measure based on values of the independent measure. Specifically, regression was used to determine if self-control was a correlate of school violence victimization. OLS regression is unsuitable for dichotomous variables because OLS regression requires 
the variable to be normally distributed on the Y-axis (Field, 2003; Menard, 2002). With a dichotomous dependent variable, there are only two response categories, making the distribution clustered at the two responses (Menard, 2002). When used on a dichotomous variable, OLS regression has the potential to return slope results greater than 1 or less than zero, which is incorrect (Field, 2003; Menard, 2002). Binary logistic regression addresses this shortcoming by accommodating for the distribution issue. Binary logistic regression provided valuable information about the odds (i.e., odds ratio) of school violent victimization occurring. The odds ratio can be defined as, "The odds of an event occurring in one group compared to another" (Field, 2003; p.790). Represented by $\operatorname{Exp}(B)$, the odds ratio represents the difference in chance that a particular outcome will or will not happen. It is derived from odds scores, which represent the probability of an event occurring over the probability of the event not occurring (Field, 2003).

Step 4 of the analysis performs the same analysis as step 3, with the difference being that the logistic regression is split by sex. By splitting the sample used in the general violent school victimization model into male and female, the analysis will be able to understand how the independent variables predict violent school victimization for each sex separately. This information can tell us if each predictor operates the same across biological sex, or if the variables act differently for males as opposed to females.

The final step in the analysis, step 5, involves the use of Z-scores in order to compare the odds scores between males and females on predictors of violent school victimization. Using Paternoster and colleagues' (1998) equation, the analysis can correctly compare the odds scores between males and females. This method will allow us to correctly compare odds across separate samples in order to understand the differing 
magnitude of predictive power that the independent variables have on violent school victimization.

Table 2. Analytic Plan Nature of Analysis Hypothesis or Proposition Tested

Procedure

Step 1:

Descriptives
Normally distributed variables
Observe the mean, standard deviation, skewness $(<3)$ and kurtosis $(<10)$ to ensure that the do not violate acceptable limits.

Correlation coefficient.

Step 2:

Association of measures

Step 3:

Examination of the effect of independent variables with school violent victimization

Step 4:

Examination of the effect of independent variables with school violent victimization with data split by sex

Step 5:

Test of equality for the slope for male versus female victimization.
Do the measures share a common variance

Self-control, deviant peer associations, and demographic measures will effect school violent victimization

Self-control, deviant peer associations, and demographic measures will effect school violent victimization by sex

Slope of items for male victimization will be different than slope for females.
Binary Logistic Regression (general). Tolerance via OLS regression.

Binary Logistic Regression (split sex). Tolerance via OLS regression.

$\mathrm{Z}$ - score Paternoster et al. (1998). 


\section{CHAPTER 4}

\section{RESULTS}

The purpose of this study is to empirically test the predictive factors associated with sex differences in violent victimization in the school atmosphere; specifically the predictive ability of self-control, deviant peer association, and/or demographic measures. This will be done by performing a whole sample and then a sex split-sample logistic regression analysis in order to observe the predictive ability of the independent variables across biological sex.

To accomplish the goals of the current study, the analysis consists of five sections. First, the descriptive statistics will be analyzed to ensure that the data is normally distributed and does not violate any assumptions necessary to the analysis, describing the general trends of self-control, and violent victimization in the sample, as well as the demonstration characteristics of the sample in regard to sex, race, and age. Step 2 will involve the use of a correlation analysis to begin to get an understanding of the complex nature of violent school victimization. Step 3 will utilize logistic regression analysis to test the predictive power of self-control, deviant peer associations, and demographic measures on violent school victimization. Step 4 will perform a logistic regression analysis in the same manner as step 3, except that the sample will be split in SPSS, allowing for the analysis to see the predictive power of self-control, deviant peer associations, and demographic indicators according to sex. Lastly, step 5 will use zscores to measure the difference in slope between the predictive ability of the 
independent variables on violent school victimization according to sex. This test allows us to reliably and accurately state that there is a significant difference in the predictive ability of a variable between sexes, in regard to predicting violent school victimization.

\section{Step 1: Descriptive Statistics}

Before an analysis is performed using the information provided by the study, the characteristics of the data must be considered in data analysis in order to ensure that the normally distributed as well as the demonstration characteristics of the sample in regard to sex, race, and age. Skewness and kurtosis are both within the maximum allowable limit, confirming that this data is normally distributed. 
Table 3: Descriptive Statistics

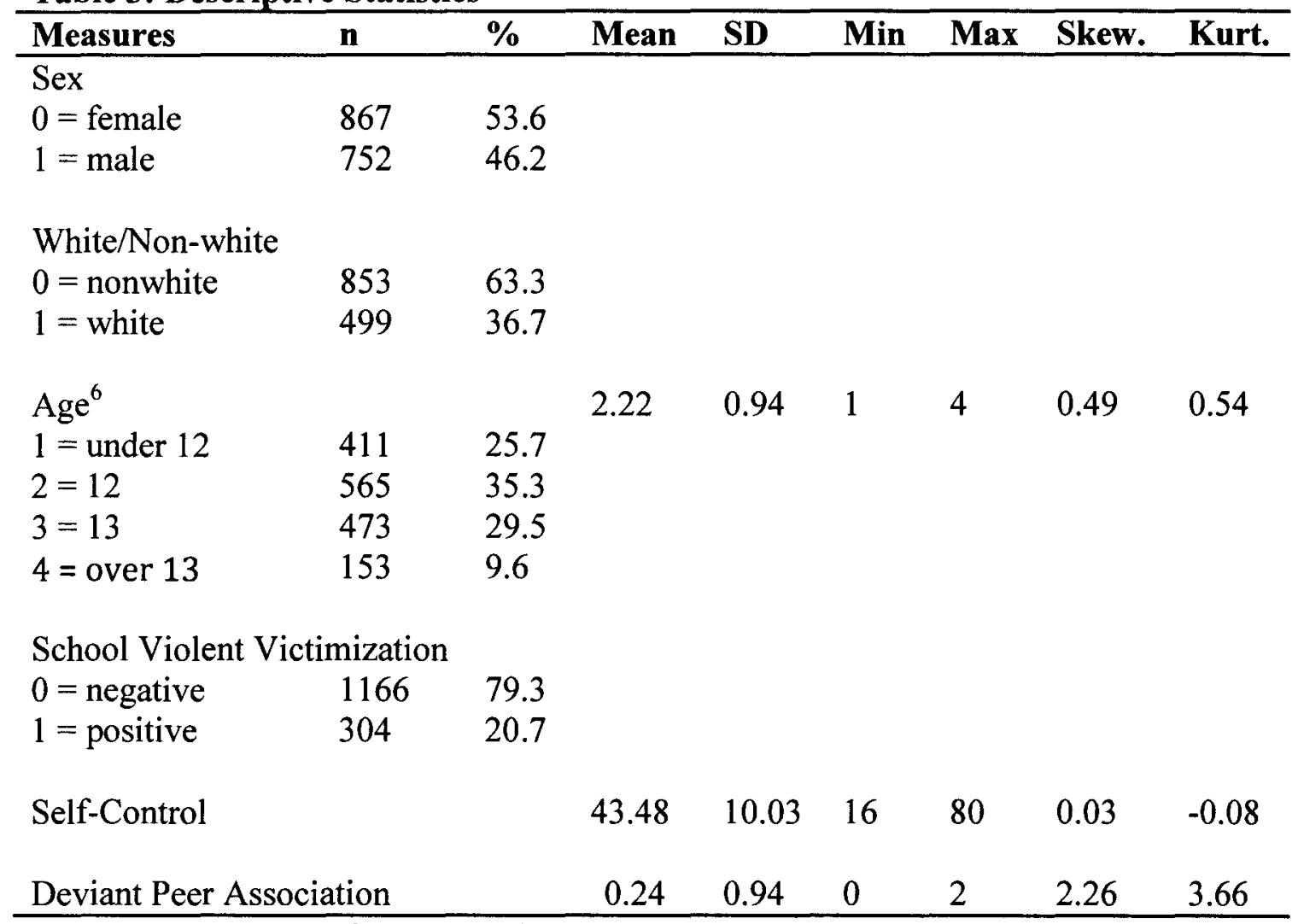

${ }^{6} \mathrm{Age}$ range is 10 to 16 (Esbensen, 2011).

Table 3 presents descriptive statistics for all of the variables included in the study. Over $46.4 \%$ of our survey respondents were male, with $53.6 \%$ being females. Study participants were classified into white (36.3\%) and nonwhite (63.7\%). Levels of violent victimization (21\%) are higher than violent victimization levels reported by Dinkes and colleagues (2010) who found violent victimization rates of 18 per 1,000 students (2\%) nationwide had been involved in some type of violent school victimization. This variation in violent victimization could be the result of the item used in this study being much more general than that used by Dinkes et al. (2010) who had separate categories for violent victimization, threats of victimization, and involvement in physical altercations, which could all be captured by the victimization measurement utilized in the present study. This 
suggests that students in the sample are at a relatively high risk for victimization when compared to a national sample.

The average score for self-control was 43.48 , indicating that, as a whole, the sample populations self-control was not overly high or low. The average for deviant peer associations was 0.24 . This means that a majority of the sample did not report any deviant peer associations.

\section{Step 2 Associations of Measures}

Table 4 shows the zero-order correlations between the independent and dependent variables. The important relationships will be discussed in this section. When looking at the relationship of the independent variables and control variables, self-control $(r=0.13)$, deviant peer associations $(r=0.14)$, and $\operatorname{sex}(r=0.06)$ were all significantly correlated to violent school victimization. This means that students with a greater number of deviant peer associations and lower levels of self-control are more likely to experience a greater level of violent school victimization. Males were also more likely to experience violent school victimizations than females.

Table 4: Correlation Matrix

\begin{tabular}{lcccccc}
\hline \multicolumn{1}{c}{ Measure } & 1. & 2. & 3. & 4. & 5. & 6. \\
\hline 1.Violent School Victimization & 1.00 & $0.13^{* *}$ & $0.14^{* *}$ & -0.02 & $0.06^{*}$ & 0.06 \\
2. Self-Control & & 1.00 & $0.30^{* *}$ & 0.10 & $0.12^{* *}$ & $-0.16^{* *}$ \\
3. Deviant Peer Association & & & 1.00 & $0.23^{* *}$ & $0.07^{* *}$ & $-0.10^{* *}$ \\
4. Age & & & & 1.00 & 0.04 & $-0.08^{* *}$ \\
5. Sex & & & & & 1.00 & $0.65^{*}$ \\
6. Race & & & & & & 1.00 \\
\hline
\end{tabular}

* significant at the 0.05 level

** significant at the 0.01 level

Females were found to have higher levels of self-control than males $(r=0.12)$. Similarly, lower levels of self-control were correlated with higher levels of deviant peer 
associations $(r=0.30)$. This indicates that students with lower levels of self-control were also associating with deviant peers. Additionally, race was negatively correlated to selfcontrol $(r=-0.16)$. This correlation suggests that white students had higher levels of selfcontrol than non-white students.

Deviant peer associations were found to have positive correlations with violent school victimization $(r=0.14)$ self-control $(r=0.30)$ age $(r=0.23)$ and $\operatorname{sex}(r=0.07)$ as well as being negatively correlated to race $(r=-0.10)$. Those who reported deviant peer associations were more likely to be victims of violent school victimization, have lower levels of self-control, are older, male, and non-white. The strength of the correlation between self-control and deviant peer associations as well as their correlations with violent school victimization suggests that both must be considered due to their close relationship.

Taken together, the present analysis can begin to understand the relationships between the independent variables and violent school victimization. Self-control, deviant peer associations, and biological sex are all related to violent school victimization. In the next section, a multivariate analysis will be utilized in order to understand how the combination of these variables work to predict violent school victimization occurrence.

\section{Step 3: General Violent School Victimization}

Two binary logistic regressions will be used to show the relationships of the selfcontrol, deviant peer association, and demographic indicators to violent school victimization. In order to ensure the models and approach fit the data, the following goodness of fit statistics will be utilized: 
1. Model chi-square statistic: Chi-square is used as a goodness-of-fit statistic to evaluate the performance of the proposed model versus the constant (Field, 2003). When this is a positive number and is also statistically significant, the goodnessof-fit for the existing model can be proven. Additional statistics should be analyzed because of the measures of sensitivity to sample size (Field, 2003).

2. Percent correct predictions: This information is obtained from the classification table and indicates how well the model predicts group membership into your dichotomous dependent variable (Field, 2003). The higher this statistic is represents the greater prediction that the constructed model is able to achieve.

3. -2 Log likelihood: Log likelihood refers to the amount of unexplained information there is after the model has been fitted. This number is multiplied by -2 to give the value a chi square distribution.

This analysis will use both a general and a sex-stratified model. This approach will highlight the effects of the independent variables on violent school victimization according to sex, giving us sex-specific odds ratio scores and allowing us to better understand whether the victimization indicators operate differently by sex. The following sections are separated in terms of the hypothesis posed in Chapter 2, with general violent school victimization being followed by female and then male sex-stratified versions of the binary logistic regression analysis.

H1: Self-control, deviant peer association, age, sex, and race will affect school violent victimization.

The dependent variable measures school violent victimization using a response of 0 if they experienced no violent victimization and 1 if they had experienced some type of 
behavior that qualified as violent school victimization. The following binary logistic regression model is used in an attempt to identify a good set of measures that can predict violent victimization of children while at school. Overall the results shown at the bottom of Table 5 indicate that the general school victimization model was acceptable, the model chi-square value generated was significant $\left(\chi^{2}=49.95, \mathrm{p}=0.000\right)$, indicating that the model was significantly more reliable at predicting violent school victimization than the null model. The model fit statistics indicated an acceptable fit with a -2 log likelihood model fit index of 933.17, which is partially a result of the large sample size. Overall, the model was found to predict $78.8 \%$ of the responses correctly, suggesting that the model is a good fit to the data. In step 3, collinearity was not found to be an issue for any of the variables utilized in the general sample. All values were over 0.88 , which is above the 0.20 threshold suggested by Menard (2002).

Table 5: General Violent School Victimization

\begin{tabular}{lcccc}
\hline \multicolumn{1}{c}{ Measures } & B & SE & $\operatorname{Exp(B)}$ & Tolerance \\
\hline Self-Control & $0.03^{*}$ & 0.01 & 1.03 & 0.88 \\
Deviant Peer Associations & $0.65^{* *}$ & 0.18 & 1.92 & 0.86 \\
Sex & 0.13 & 0.17 & 1.14 & 0.96 \\
White/Non-white & $0.48^{* *}$ & 0.17 & 1.62 & 0.96 \\
Age & $-0.19^{*}$ & 0.09 & 0.83 & 0.94 \\
-2LL & 933.17 & & & \\
Cox \& Snell R & 0.05 & & & \\
Nagelkerke R & 0.08 & & & \\
Model Chi Square & 49.65 & & & \\
\hline
\end{tabular}

* significant at the 0.05 level

** significant at the 0.01 level 
The first hypothesis is not satisfied by the general model of violent school victimization, because biological sex was not a significant predictor of violent school victimization. Even though they failed to reject the null hypothesis, this set of findings has interesting implications for the hypothesis. Sex is the only predictor that failed to reach significance in the general model, suggesting that the other predictors in the model may be more important in understanding violent school victimization. Perhaps most surprising was the non-significance of sex in this general model, which works contrary to the findings of prior victimization literature (Schreck, 1999). This also does not conform to victimization literature that states that females are less likely than males to be victimized in school (Dinkes et al., 2010).

Other variables were found to successfully predict violent school victimization. Specifically, the odds ratio for self-control, $\operatorname{Exp}(B)=1.03$, indicating that individuals with lower levels of self-control will be $3 \%$ more likely to be a victim of violence at school per unit increase in self-control. This finding is supported by prior literature that posits that those with lower levels of self-control are more likely to be victimized than those that with higher levels of self-control (Schreck, 1999). The scores for deviant peer associations were surprising, $\operatorname{Exp}(B)=1.92$, indicating that for each unit increase in deviant peer association, violent school victimization risk increased $92 \%$. This is consistent with prior research that has found that lower levels of self-control and greater deviant peer associations are indicative of higher levels of victimization at school (Sullivan et al., 2011). The demographic indicators revealed that those who are white, $\operatorname{Exp}(B)=1.62$, are $62 \%$ more likely to be victimized than nonwhite peers, as well as those that are older, $\operatorname{Exp}(B)=0.83$, are $17 \%$ less likely to be victimized then their 
younger peers per one unit increase, which is consistent with the findings of Schreck and Fisher (2004).

Because sex did not play a significant role in predicting victimization, the first null hypothesis cannot be rejected. Regardless of the fact that sex was not found to be an important predictor of violent victimization, another logistic regression analysis will be

performed, this time with the sample group split by sex to better understand the effects of the other variables on biological sex.

\section{Step 4: Sex-Specific Violent School Victimization}

Moving past the general victimization logistic regression analysis, this section of the analysis will address the sex-specific school victimization models. This sex-specific nature of these models was performed by separating the data by sex, allowing us to isolate the effect of the violent school victimization predictors by sex. Performing this analysis will allow the present study to see if each of the predictors operates the same across sex lines.

H2: Self-control, deviant peer association, age, and race will affect female school violent victimization.

Overall the results shown at the bottom of Table 6 indicate that the female school violent victimization model was acceptable, the model chi-square value generated was significant $\left(\chi^{2}=33.41, p=0.000\right)$, indicating that the model was significantly more reliable at predicting violent school victimization than the null model. The model fit statistics for female school violent victimization, Table 6, indicated an acceptable fit with a $-2 \log$ likelihood model fit index of 456.98 , which is partially a result of the large sample size. Overall, the model was found to predict $81.5 \%$ of the responses correctly, 
suggesting that the model is a good fit to the data. In step 4, collinearity was not found to be an issue for any of the variables utilized in the female sample. All values were over 0.86 , which is above the 0.20 threshold suggested by Menard (2002).

The hypothesis was only partially supported by the results of the female-specific logistic regression. The results for the female-only violent victimization logistic regression found that all of the predictors were significant except for race. Specifically, the odds ratio for self-control, $\operatorname{Exp}(B)=1.03$ indicating that individuals with lower levels of self-control will be $3 \%$ more likely to be a victim of violence at school per unit increase in self-control. The scores for deviant peer associations were surprising, $\operatorname{Exp}(B)$ $=2.84$, indicating that those that associate and participate in deviant peer groups are $184 \%$ more likely to be violently victimized at school than those who do not associate with deviant peer groups per unit increase in deviant peer associations. This finding is similar to that of McGloin and Shermer (2009) who found that deviant peer associations played a larger role in delinquent activities for females than they did for males. This finding suggests that females are more susceptible to victimization risk because the activities that their deviant peer group participates in places them in a position to be victimized.

The only demographic indicator that remained significant was age, $\operatorname{Exp}(B)=0.70$, indicating that a one-unit increase decreased instances of violent victimization by $30 \%$. For females, race is not an important indicator when attempting to predict violent victimization at school. Because race was found to be nonsignificant for females, only partial support can be given for hypothesis three. 
Table 6: Violent School Victimization - Sex Differences

\begin{tabular}{lcccccccc}
\hline & \multicolumn{9}{c}{ Male } & \multicolumn{5}{c}{ Female } \\
\hline \multicolumn{1}{c}{ Measures } & B & SE & Exp(B) & Tolerance & B & SE & Exp(B) & Tolerance \\
Self-Control & $0.03^{*}$ & 0.01 & 1.03 & 0.92 & $0.03^{*}$ & 0.01 & 1.03 & 0.86 \\
Deviant Peer & $0.43^{*}$ & 0.18 & 1.54 & 0.87 & $1.05^{* *}$ & 0.23 & 2.84 & 0.86 \\
Associations & & & & & & & & 0.92 \\
White/Non-white & $0.61^{* *}$ & 0.23 & 1.83 & 0.98 & 0.35 & 0.25 & 1.42 & 0.93 \\
Age & -0.07 & 0.13 & 0.93 & 0.95 & $-0.35^{* *}$ & 0.14 & 0.70 & \\
-2LL & 469.42 & & & & 456.98 & & & \\
Cox \& Snell R & 0.04 & & & & 0.06 & & & \\
Nagelkerke R & 0.06 & & & & 0.10 & & & \\
Model Chi Square & 19.29 & & & & 33.41 & & &
\end{tabular}

* significant at the 0.05 level

** significant at the 0.01 level 
H3: Self-control, deviant peer association, age, and race will affect male school violent victimization.

Overall, the results shown at the bottom of Table 6 indicate that the male school violent victimization model was acceptable, the model chi-square value generated was significant $\left(\chi^{2}=19.29, p=0.001\right)$, indicating that the model was significantly more reliable at predicting violent school victimization than the null model. The model fit statistics for male school victimization, Table 6 , indicated an acceptable fit with a $-2 \log$ likelihood model fit index of 469.62 , which is partially a result of the large sample size. Overall, the model was found to predict $76.2 \%$ of the responses correctly, suggesting that the model was a good fit for the data. In step 4, collinearity was not found to be an issue for any of the variables utilized in the male sample. All values were over 0.87 , which is above the 0.20 threshold suggested by Menard (2002).

The hypothesis was only partially supported by the results of the male-specific logistic regression. The results for the male-only violent victimization logistic regression found that all of the predictors were significant except for age. Specifically, the odds ratio for self-control, $\operatorname{Exp}(B)=1.03$, indicating that individuals with lower levels of selfcontrol will be $3 \%$ more likely to be a victim of violence at school per unit increase in the self-control. Deviant peer associations received an odds ratio of $\operatorname{Exp}(B)=1.54$, indicating that those that associate and participate in deviant peer groups are $54 \%$ more likely to be violently victimized at school than those who do not associate with deviant peer groups per unit increase in delinquent peer associations.

The demographic indicators revealed that those who are white, $\operatorname{Exp}(B)=1.83$, are $83 \%$ more likely to be victimized than nonwhite peers. This finding is consistent with 
Hannish and Guerra (2000) that found that white male students had some of the highest rates of victimization among all students that were sampled. Researchers also found that white students that were enrolled in primarily minority schools had the highest rates of victimization (Hannish \& Guerra, 2000). Although the makeup of each school cannot be confirmed due to the blinded nature of the data, the demographic information suggests this is the case for the sample. Age was the only predictor that was nonsignificant for the male sample, suggesting that age does not play a significant role in violent victimization escalation or desistence in the sample. Because age was found to be nonsignificant for males, only partial support can be given for hypothesis three.

\section{Step 5: Z-Scores}

Using a z-score allows us to examine the interactive effects of the predictor variables across the independent male and female samples. This is done using the equation by Paternoster, Brame, Mazerolle, and Piquero (1998), which utilizes the odds (B) and the standard error (S.E.) from each sample's predictor variables to create a composite slope score. This score explains the different operation of the variable between the samples. The results for $z$-score calculations are presented in Table 7.

\section{Table 7: Z-Scores for Sex Differences in Violent School Victimization}

\begin{tabular}{ll}
\hline Measures & Z-Score \\
\hline Self-Control & 0.00 \\
Deviant Peer Associations & 7.29 \\
White/Non-white & -2.24 \\
Age & -10.74 \\
\hline
\end{tabular}

The results of the z-score calculations reveal some interesting findings within the data. According to the z-score results in Table 7, the effect of self-control on violent school victimization remained steady for both male and female samples. This finding 
supports Gottfredson and Hirschi's (1990) statement that self-control theory is a genderneutral; that is, that it works equally well for males and females in the explanation of crime and delinquency.

For males, demographic predictors like white/nonwhite and age had a far more pronounced effect on violent school victimization than they did for females. This suggests that there is some underlying trait that leads to a higher rate of victimization for males that is outside of social structure (deviant peer association).

While violent school victimization increased for both males and females when associating with deviant peers, this effect was significantly more pronounced among females, which is inconsistent with prior literature (Mears, Ploeger, \& Warr, 1998). This means that for females, deviant peer associations play an important role in school violent victimization occurrence. For females, occurrences of victimization are predicted far less by demographic indicators than the male sample.

Overall, the information from the z-score analysis has found that, with the exception of self-control, the items in the models used to predict violent school victimization are operating very differently between males and females. This suggests that one predictive model may not provide an adequate explanation for violent school victimizations across biological sexes. 


\section{CHAPTER 5}

\section{DISCUSSION}

Gottfredson and Hirschi (1990) published their version of self-control over two decades ago. Low self-control has been consistently linked to many criminal and deviant behaviors, ranging from cutting class by college student to serious street crimes. Because of the large number of empirical studies, low self-control has been considered one of the strongest correlates of crime (Pratt \& Cullen, 2000). Although Gottfredson and Hirschi (1990) originally created self-control theory as an explanation of various forms of criminal activity, it has recently been extended as an explanation for higher rates of victimization (Baron, Ford, \& Kay, 2007; Piquero et al., 2005; Schreck, 1999; Schreck, Stewart, \& Fisher, 2006; Schreck, Wright, \& Miller, 2002; Sullivan, Wilcox, \& Ousey, 2011; Taylor, Peterson, Esbensen, \& Freng, 2007; Wilcox, Tillyer, \& Fisher, 2009).

The purpose of the present study is to better understand the predictors associated with differences in male and female violent victimization at school. Specifically, this study seeks to understand the predictive ability of self-control in explaining both general and sex-specific models of victimization when deviant peer associations and demographic variables are included. Understanding if there are differences in predictors of victimization according to biological sex is a largely uncharted territory that can offer insights into its causes and effects. 


\section{Summary of Results}

This section will summarize the results of the present study. Because this study had two different logistic regression analyses that stemmed from three hypotheses, this section will be organized in a manner to address each analysis separately.

H1: Self-control, deviant peer association, age, sex, and race will affect school violent victimization.

In the general model, the study the model containing self-control, deviant peer associations, and demographic independent variables were utilized in an attempt to predict violent school victimization. Specifically, the results show that low levels of selfcontrol increase the likelihood of violent victimization at school. These results are consistent with previous research that has shown that low self-control has a link with victimization in the school environment (Nofziger, 2009; Schreck, Wright, \& Miller, 2002). This result is robust in that other variables that are related to victimization were included and were not able to falsify the link between low self-control and violent victimization at school.

The analysis also revealed that self-control was not the strongest predictor of violent victimization; instead deviant peer associations were found to have the largest predictive ability in the model. This finding is not surprising in light of the work from Pratt and Cullen (2000) that found that self-control has failed to remove the effect of peer associations, and as such they must be included in an analysis of self-control to ensure that the results are robust. Those with delinquent peers could be at a greater risk of victimization because they themselves are more likely to commit violent acts. Herrenkohl and colleagues (2000) found that deviant peer associations were among the most 
influential risk factors in elevated youth violence for 10,14 , and 16 year old students (see also Huang, Kosterman, Catalano, Hawkins, \& Abbott, 2001). This would be in line with research that states that victims and offenders share similar traits, and often overlap (Lauritsen et al., 2008; Mustaine \& Tewksbury, 1998; Woodward \& Fergusson, 2000), suggesting that those who commit violence together are also more likely to be victimized together. While there is relatively little literature that addresses the role of deviant peers on victimization outcomes, Tillyer and colleagues (2011) found that deviant peer associations increased violent victimization risk more than self-control (see also Schreck et al., 2002). Schreck, Fisher, and Miller (2006) have found that those that are centrally located or in a dense deviant peer network are more likely to be the victims of violent victimization than individuals without deviant peer networks.

Demographic indicators still presented significant results, in addition to those presented by self-control and deviant peer associations. Consistent to prior victimization literature, those that are younger have a higher victimization risk in the school environment (Schreck, 1999; Schreck \& Fisher, 2004). In addition to age as a significant predictor of violent victimization, individuals who were white were more likely to be victimized than those who were in the non-white category. This differs from a majority of the literature that states that minorities are more likely to be victimized than whites (Nofziger, 2009; Schreck, 1999; Schreck et al., 2006), but has been found in previous work (Tillyer et al., 2011). The sample for the present study was drawn from a minorityheavy sample, meaning that this finding could be a result of the higher minority representation. Although the racial composition of each school cannot be precisely tallied, these higher victimization rates for the white racial group could be a result of its minority 
status within that particular school. This is supported by the findings of Hannish and Guerrera (2000) who found that white students in a primarily minority school were at a higher risk for victimization and violence than in a primarily white school.

Perhaps the most important finding from the demographic indicators was the nonsignificance of sex to victimization occurrence. This result suggests that the predictors used in the present study were able to explain victimization across biological sex, making sex nonsignificant in violent school victimization risk. Prior literature has not been able to negate the effects of sex in victimization occurrence (Nofziger, 2009; Schreck, 1999; Schreck et al., 2002; Wilcox et al., 2009). The nonsignificance of sex in the general model suggests that self-control, deviant peer associations, age, and race are able to accurately predict victimization occurrences across male and female populations.

The answer to the first research question is "partially." The findings demonstrate the utility of self-control, deviant peer association, age, and race are all effective and significant predictors of victimization. Biological sex is not an effective predictor of victimization when accounting for the other predictors of victimization in the model. Overall, the model was able to effectively predict violent school victimization and to explain violent school victimization across biological sex.

H2: Self-control, deviant peer association, age, and race will affect female school violent victimization.

H3: Self-control, deviant peer association, age, and race will affect male school violent victimization.

Moving beyond the general model and applying the same independent variables to a split-sex sample, the study was able to understand how the predictors operate 
differently for males and females. Self-control was the only predictor that was consistent across sexes, which is consistent with Gottfredson and Hirschi's (1990) assertion that the general theory of crime is sex-neutral. Once again, self-control was a robust predictor for both sexes, remaining significant net of the inclusion of the other variables related to victimization. The results for both sexes indicate that other measures in addition to selfcontrol are important in understanding and predicting violent victimization at school.

Females and males were found to have very different predictors for violent school victimization with the exception of self-control levels. Deviant peer associations were played an important role for females, indicating that females who associate with deviant friends are more likely to be victims of violent victimization than those who do not have deviant peers. Although there is very little literature addressing peer deviance and victimization, this finding is similar to Tillyer et al. (2011), who found that delinquent peers played a larger role in violent victimization for females than males. Wilcox et al. (2009) found that association with deviant peers was not only one of the strongest indicators of assault and theft victimization, it was also a more effective indicator for females than males.

As opposed to females, males' victimization occurrences were more heavily predicted by demographic variables such as age and race. This finding is consistent with the original model, and is supported by the literature. Peer delinquency was again a strong indicator of victimization, but was overshadowed by the score for race, which had the overall highest predictive ability. This finding is again supported by the findings of Hannish and Guerrera (2000) who found that white students in a primarily minority school were at a higher risk for victimization and violence than in a primarily white 
school. Another possibility lies in the explanation given by Popp and Piguero (2011) that white students are more likely to report victimization occurrences than minority students. Regardless of the reasoning, demographic indicators were found to operate better for males than for females.

The answers to the second and third hypotheses are "partially". For females, selfcontrol deviant peer associations, and age were all effective predictors of victimization, while race was not a significant predictor of violent school victimization. For men, selfcontrol, deviant peer associations, and race where all significant predictors of violent school victimization, while age was not significant. These findings demonstrate the utility of self-control and deviant peer associations in understanding violent school victimization. Perhaps more importantly, these findings highlight the importance of additional demographic indicators, as well as how different items operate according to biological sex. These findings suggest that the models for violent school victimization for males and females may not be that different.

\section{Theoretical Implications}

Gottfredson and Hirschi (1990) suggest, while familial socialization is the strongest source of self-control development, that the second socializing area is the school. At the school, teachers or school administrators are able to perform similar tasks as parents during the pivotal period of self-control development. Specifically, teachers or school administrators are able to enact the parental socialization functions that are required to instill self-control in youth: they develop attachments to their students, regularly supervise, analyze of behavior, and provide non-corporal punishment for antisocial behavior. 
The school has several advantages over the family in its ability to instill selfcontrol: they can more effectively supervise the children, ability to easily recognize delinquent behavior, and punishment of delinquent activities because, at school age, those at the school, have longer and consistent contact with the children. Turner, Piquero, and Pratt (2005) examined the role of the school in the development of self-control by examining teacher socialization behaviors. They show that schools were able to affect self-control in addition to parental management, and that school socialization was evident across community contexts (Turner et al., 2005), suggesting that this theoretical implication is a worthwhile avenue for further exploration.

\section{Policy Implications}

In education, creating or improving the school environment's level of safety for students would seem to be an important policy implication from this research. The school environment should effectively address any and all victimization risks in order to ensure that education is the main focus for students, not fear of victimization. The findings of the present study suggest that improving self-control and reducing deviant peer associations could be an effective solution. Hawkins and Catalano's (1996) social development model encompasses many of the themes that are present in both self-control theory and social learning theory.

The social development model seeks to explain why both prosocial and antisocial behaviors develop over the course of a child's socialization (Catalano \& Hawkins, 1996; Hawkins, Farrington, \& Catalano, 1998). It views these prosocial and antisocial behaviors as a product of the interaction between a child and their environment (Catalano \& Hawkins, 1996). This environment is made up of individual, family, school, peer group, 
and community domains, each of which provides risk and protective factors for delinquency and crime (Catalano \& Hawkins, 1996). Risk factors include: Poor family management practices, low family bonding, early and persistent problem behavior, academic failure, peer rejection in elementary school, association with delinquent peers, aggression, and rebelliousness (Catalano \& Hawkins, 1996). Protective factors include: Resilient temperament, positive social orientation, intelligence, family warmth, and external social supports that reinforce an individual's prosocial activities and beliefs (Catalano \& Hawkins, 1996).

Looking at the risk factors presented by the social development model, they are in fact components of self-control and deviant peer associations. An individual with a low level of self-control is the result of ineffective parental management and warmth. It would also be expected for a child with low levels of self-control to exhibit persistent problem behaviors as a result of their inability to resist immediate gratification.

Academic failure would also be expected because the benefits of education are long-term and individuals with low self-control lack the ability to plan for long-term benefits.

Schools that work to reduce risk factors, while also increasing protective factors for the student will be the those that are most effective at reducing the risk of violence at school (Hawkins, Farrington, \& Catalano, 1998). Schools can begin to accomplish this reduction by addressing the decision-making and social dynamics of students, thus helping students develop higher levels of self-control and lower levels of deviant peer associations. With students, social interaction skills (communication, conflict resolution, and negotiation) and problem solving skills (decision making/problem solving) should be taught in schools in order to reduce negative peer influences and raise self-control 
(Catalano \& Hawkins, 1996). Parents must be taught proper parental management skills including supervision, analysis of behavior and age-appropriate noncorporal punishment. Teachers and administrators can become involved in improving a child's level of selfcontrol by presenting clear expectations of conduct, and addressing student's shortcomings to increase academic success (Gottfredson \& Hirschi, 1990).

Researchers have found that programs aimed at increasing self-control are widely effective across a variety of situations and participants (Piquero, Jennings, \& Farrington, 2010). These programs consistently reported high effect sizes across various different programs and school systems. To be most effective research generally finds that interventions should be introduced early in the life of a child in order to effectively address behavior issues (Gottfredson \& Hirschi, 1990; Piquero et al., 2010).

The Fast Track Program targets the primary risk factors for antisocial behavior, including poor parenting practices, lacking social problem-solving and emotional coping skills, poor prosocial peer relations, weak academic skills, disruptive classroom environments, and poor home-school relations (Conduct Problems Prevention Research Group, 1999). This program begins at the $1^{\text {st }}$ grade level and has continued age appropriate interventions up to $10^{\text {th }}$ grade (Conduct Problems Prevention Research Group, 1999).The Fast Track program utilizes a unified model of prevention, which includes two levels of intervention: Universal and selective components. This allows the program to address the school as a whole, as well as the individuals in the school who are at a high risk for conduct problems and violence in school (Conduct Problems Prevention Research Group, 1999). 
The universal component of the Fast Track intervention is aimed at covering all the students within the school that it is administered from the $1^{\text {st }}$ grade forward (Conduct Problems Prevention Research Group, 1999). Teachers deliver two to three lessons per week for the entire school year that addresses four domains of skills. These skills are: (1) kills for emotional understanding and communication, friendship skills (such as participation, identifying prosocial peer groups, cooperation, fair play, and negotiation), self-control skills (such as behavioral inhibition and arousal modulation), and social problem-solving skills (problem identification, response generation, response evaluation, and anticipatory planning) (Conduct Problems Prevention Research Group, 1999). In this component of the Fast Track intervention, teachers regularly meet with Fast Track Educational Coordinators in order to ensure that the program is implemented correctly and that classroom management practices are appropriate.

The selective intervention component of the Fast Track intervention focuses on the children and parents that were found to be at a high-risk for conduct problems at school (Conduct Problems Prevention Research Group, 1999). For the $1^{\text {st }}$ grade, these meetings are held once per week for 22 weeks, moving to a biweekly schedule for the $2^{\text {nd }}$ grade, and to a monthly meeting from the $3^{\text {rd }}$ grade forward. Parent groups, child social skill training groups, and academic tutoring are held as an afterschool program on weekdays or Saturdays. Parent groups are designed to establish a positive family-school relationship, build parental self-control, promote appropriate expectations of child's behavior, and improve parenting skills (Conduct Problems Prevention Research Group, 1999). Children are also placed in friendship groups that built upon the domain skills taught in the universal portion of the Fast Track program. Biweekly home visits allow 
field coordinators to work with children and parents to generalize the social skills that the child is learning and promote parental support of the child's school adjustment (Conduct Problems Prevention Research Group, 1999).

High-risk students also receive assistance with schoolwork on a one-on-one basis from professional tutors three times a week (Conduct Problems Prevention Research Group, 1999). These tutors work with students to improve reading comprehension as well as peer relationships using peer pairing. Peer pairing is an activity that involves two onehour supervised sessions per week where high-risk students are placed with other students in the classroom (Conduct Problems Prevention Research Group, 1999). This activity facilitates generalized friendship skills and implementation of social skill concepts taught to the class as a whole.

Researchers have found that the participants in the Fast Track program showed significant progress in their acquisition in emotional and social coping skills, social problem solving skills, lower rates of aggressive retaliation, better acceptance scores from other peers and teacher, and increase reading comprehension scores (Conduct Problems Prevention Research Group, 1999). In addition, the Fast Track program was able to significantly affect parental warmth, management, and punishment scores (Conduct Problems Prevention Research Group, 1999). Taken together, the Fast Track program was able to reduce antisocial behaviors in students in school, increase school performance, and improve the parental management tasks of parents who were involved in the program. Further, Piquero et al. (2010) found that the Fast Track program had one of the stronger effect sizes out of all self-control programs observed in their systematic review. 
The success of this program has been shown to remain into the $5^{\text {rd }}$ grade with lower levels of antisocial behaviors reported by teachers and lower levels of aggressive behavior reported by parents (Conduct Problems Prevention Research Group, 2002). Researchers also found that risk for peer delinquency and or conduct problems was reduced through the end of elementary school, supporting assertions that the Fast Track program is successful throughout elementary school (Conduct Problems Prevention Research Group, 2002). After 5 years, $22 \%$ of the intervention-group children were classified as clinical cases (with conduct-disordered behavior) in the home and community context in contrast with $29 \%$ of control children (Conduct Problems Prevention Research Group, 2004). After ninth grade, intervention-group children reported lower rates of self-reported antisocial behavior and peer deviance (Conduct Problems Prevention Research Group, 2011).

This program lowers the risk factors and raises the protective factors associated with a reduction in antisocial behaviors. Students are taught prosocial peer interaction skills and social cognitive skills in order to better relate to prosocial classmates and desist antisocial peer groups. In addition, the emotional and behavioral inhibition training as well as better teacher management will raise levels of self-control and reduce aggressiveness toward teachers and other students. For students at high a high risk of violence and conduct problems, the school can address parental management issues by including the parents of the child in the selective intervention program, which can positively affect self-control.

The limitations of the Fast Track program exist in its implementation. To be effective, this program must operate throughout the entire school, and must continue 
through multiple grades. The Fast Track program is not a targeted intervention strategy for violence and conduct problems in the school environment. Instead, it could be viewed more as a reform to the educational system, meant to address socialization in the school context.

\section{Limitations}

As with many criminological studies, the results of the present analysis should be viewed in light of the study's limitations. First, the measurement of violent school victimization lacks content validity because it is composed of only a single item measure that fails to capture the full nature of violent school victimization. The self-control item was not measured well as there were no differences between males and females that have been demonstrated in prior research.

The sample composed in the present study was obtained through students attending public schools. This limitation reduces the ability to generalize these results to students not attending public schools. Caution should be exercised in applying these findings to students in private schools and students that are home-schooled. Additionally, since the sampling method was not random, these findings are not generalizeable.

The Community Works program is designed to assist at-risk youth with various issues ranging from drug use to violence and victimization (Esbensen, 2011). The individuals in the sample have been exposed to some of the curriculum from the program, making them more sensitive to violence; thus, their sensitivity may be affecting their rate of reporting and acknowledging instances of violence. In other words, the sensitivity of the individual based on the curriculum may be putting them in a position to report differently for the violent victimization measures. This limitation has been addressed 
within a process evaluation by Esbensen (2009), where it was found that the program was not being uniformly implemented. Nonetheless, exposure to the program curriculum needs to be considered with item responses.

Another limitation lies in the sample population itself. Due to the original nature of the data as being part of a program evaluation, it was subject the sampling procedure used and the distribution of the programs being observed. This, in its self provides two potential issues an overrepresentation of individuals with higher rates of victimization and a population that is not generalizable to the larger population. The community cares programs focus on at-risk youth means that it is more likely that the program captured the individuals that have a higher likelihood of being victimized. The schools that were involved in administering the program were likely doing so because of victimization problem, meaning that the sample population had high rates of violent victimization. Another limitation related to the sample populations generalizability to the national population due to the overrepresentation of minorities (Esbensen, 2009). This overrepresentation is due to school sample sites, which are located in primarily urban, diverse schools. The sample does match the demographics of their localities, but not the demographics of the U.S. as a whole (Esbensen, 2009).

\section{Conclusion}

In conclusion, the present study contributes several important findings to school victimization research. First, self-control is an important predictor of violent school victimization for both males and females. Other variables like deviant peer associations, age, and race are all significant predictors of violent victimization in school that explain differences between biological sexes. In addition, this study found that the predictive 
models for school victimization are different between males and females. Self-control and deviant peer associations remain effective for both males and females while the demographic indicators varied between males and females. Finally, the results indicate that, with the exception on self-control, the effectiveness of the victimization predictors varies by biological sex.

Despite the limitations of this study, self-control was found to be an important predictor for violent school victimization across biological sex and despite the inclusion of deviant peer association and demographic controls. These findings suggest that victimization is largely a result of individuals' decision-making and social relations within the school atmosphere. It may be that the current school and classroom management procedures are failing to address problem behaviors in a way that will increase self-control as well as interrupt the activities of deviant peer groups. While the present study can only speculate on this relation, future work should examine the operation of the school environment and its relationship with victimization predictors and victimization occurrence.

The results of the present study suggest that there are several avenues for future research, which are divided into three major veins: Examination of other types of victimization, examination of other predictive variables as an explanation for victimization, and looking at the effect of school management strategies on victimization in school. In future research, the relationship between other forms of victimization (nonviolent, sexual, and bullying), the current model, and biological sex in order understand if the findings from the current study can extend to other types of victimization. 
In addition to examining other types of victimization, additional criminological theories could be utilized. By examining the other theories, the current model could gain additional rigor. Additionally, these other variables may uncover another, more effective explanation for victimization in the school atmosphere. Once additional research has been performed to understand the factors associated with victimization, how they impact males and females, and what types of victimization that they address, research can improve upon the literature on effective intervention strategies. Educational professionals begin to change how schools operate and make adjustments to address victimization problems, making the school environment safe and conductive to learning. 


\section{REFERENCES}

Akers, R. L. (1998). Social Learning and Social Structure: A General Theory of Crime and Deviance. Boston, MA: Northeastern University Press.

Arneklev, B. J., Grasmick, H. G., \& Bursik, R. J. (1999). Evaluating the dimensionality and invariance of low self-control. Journal of Quantitative Criminology, 15(3), $307-331$.

Arneklev, B. J., Grasmick, H. G., \& Tittle, C. R. (1993). Low self-control and imprudent behavior. Journal of Quantitative Criminology, 9(3), 225-247.

Baron, S. W., Forde, D. R., \& Kay, F. M. (2007). Self-control, risky lifestyles, and situation: The role of opportunity and context in the general theory. Journal of Criminal Justice 35, 119-136.

Baron, S. W. (2004). Self-control, social consequences, and criminal behavior: Street youth and the general theory of crime. Journal of Research in Crime and Delinquency, 40, 403-425.

Baron, S. W. (2003). Self-control, social consequences, and criminal behavior: Street youth and the general theory of crime. Journal of Research in Crime \& Delinquency, 40(4), 403-425.

Benda, B. B. (2002). A test of three competing theoretical models of delinquency using structural equation modeling. Journal of Social Service Research, 29(2), 55-91.

Bowen, N. K., \& Bowen, G. L. (1999). The effects of crime and violence in 
neighborhoods and schools on the school behavior and performance of adolescents. Journal of Adolescent Research, 14(3), 319-342.

Burns, R., \& Crawford, C. (1999). School shootings, the media, and public fear: Ingredients for moral panic. Crime, Law, and Social Change, 32(2), 147-168.

Burrow, J. D., \& Apel, R. (2008). Youth behavior, school structure, and student risk of victimization. Justice Quarterly, 25(2), 349-380.

Burton, V., Cullen, F. T., Evans, T. D., Alarid, L. F., \& Dunaway, R. G. (1998). Sex, self-control, and crime. Journal of Research in Crime and Delinquency, 35, 123147.

Catalano, R. F., \& Hawkins, J. D. (1996). The social development model. Delinquency and crime, $149-197$.

Chapple, C. L., \& Johnson, K. A. (2007). Gender differences in Impulsivity. Youth Violence and Juvenile Justice, 5, 221-234.

Chapple, C. L. (2005). Self-control, peer relations, and delinquency. Justice Quarterly, 22(1), 89-106.

Chen, P. Y., \& Krauss, A. D. (2004). Cronbach's Alpha. In M. S. Lewis-Beck, A. Bryman, \& T. Futing (Eds.) The Sage Encyclopedia of Social Science Research Methods Thousand Oaks, Calif.: Sage, 2004.

Comrey, A. L., and Lee, H. B. (1992), A First Course in Factor Analysis (2nd ed.), Hillsdale, NJ: Lawrence Erlbaum Associates. 
Conduct Problems Prevention Research Group. (1999).Initial impact of the Fast Track prevention trial for conduct problems: I. The high-risk sample. Journal of Consulting arid Clinical Psychology, 67, 631-647.

Conduct Problems Prevention Research Group. (1999). Initial impact of the Fast Track prevention trial for conduct problems: II. Classroom effects. Journal of Consulting and Clinical Psychology, 67, 648-657.

Conduct Problems Prevention Research Group. (2002). Evaluation of the first three years of the Fast Track prevention trial with children at high risk for adolescent conduct problems. Journal of Abnormal Child Psychology, 30, 19-35.

Conduct Problems Prevention Research Group (2004). The Effects of the Fast Track Program and Serious Problem Outcomes at the End of Elementary School. Journal of Clinical Child and Adolescent Psychology, 33(4):650-661.

Conduct Problems Prevention Research Group. (2011). The effects of the Fast Track preventive intervention on the development of conduct disorder across childhood. Child Development, 82(1),331-345.

De Li, S. (2004). The impact of self-control and social bonds on juvenile delinquency in a national sample of mid-adolescents. Deviant Behavior, 25(4), 351-373.

Dinkes, R., Kemp, J., Baum, K., \& Snyder, T. D. (2010). Indicators: School crime and safety. Washington, DC: U.S. Departments of Education and Justice.

Esbensen, F. (2011). Outcome evaluation of the teens, crime, and the community/community works (TCC/CW) training program in nine cities across four states, 2004-2005. ICPSR25865-v1. Ann Arbor, MI: Inter-university 
Consortium for Political and Social Research [distributor], 2011-03-30.

doi:10.3886/ICPSR25865.v1

Esbensen, F., \& Carson, D. (2009). Consequences of being bullied: Results from a longitudinal assessment of bullying victimization in a multi-site sample of American students. Youth \& Society, 41, 209-233.

Esbensen, F. (2008). In-school victimization: Reflections of a researcher. Journal of Contemporary Criminal Justice, 24, 114-124.

Evans, T. D., Cullen, F. T., Burton, V. S., Jr., Dunaway, R. G., \& Benson, M. L. (1997). The social consequences of self-control: Testing the general theory of crime. Criminology, 35, 475-501.

Farrington, D. P., \& Ttofi, M. M. (2009) School-Based Programs to Reduce Bullying and Victimization. Campbell Systematic Reviews.

Field, A. (2003). Discovering statistics using SPSS for Widows. Thousand Oaks, CA: Sage.

Fisher, B., Sloan, J., Cullen, F., \& Lu, C. (1998). Crime in the ivory tower: the level and sources of student victimization. Criminology, 36, 671-710.

Gibbs, J. J., Giever, D., \& Martin, J. S. (1998). Parental management and self-control: An empirical test of Gottfredson and Hirschi's general theory. Journal of Research in Crime and Delinquency, 35, 40-70.

Gibbs, J. J., \& Giever, D. M. (1995). Self-control and its manifestations among university students: An empirical test of Gottfredson and Hirschi's general theory of crime. Justice Quarterly, 12, 231-255.

Gibson, C. L., Ward, J.T., Wright, J. P., Beaver, K. M., Delisi, M. (2010). Where does 
gender fit in the measurement of self-control? Criminal Justice and Behavior, $37(8), 883-903$.

Gibson, C. L., Sullivan, C. J., Jones, S., \& Piquero, A. R. (2010). Does it take a village? Assessing neighborhood influences on a children's self-control. Journal of Research on Crime and Delinquency 47(1), 31-62.

Gottfredson, M. R., \& Hirschi, T. (1990). A general theory of crime. Stanford, CA: Stanford University Press.

Gover, A. (2004). Risky lifestyles and dating violence: a theoretical test of violent victimization. Journal of Criminal Justice, 32, 171-180.

Grasmick, H.G., Tittle, C.R., Bursik, R.J., Jr., \& Arneklev, B.J. (1993). Testing the core empirical implications of Gottfredson \& Hirschi's general theory of crime. Journal of Research in Crime \& Delinquency, 30(1), 5-29.

Hannish, L.D., \& Guerra, N. G. (2000). The roles of ethnicity and school context in predicting childrens' victimization by peers. American Journal on Community Psychology, 28(2), 201-223.

Hashima, P. Y., Finkelhor, D. (1999).Violent victimization of youth versus adults in the national crime victimization survey. Journal of Interpersonal Violence, 14, 799820.

Hardwick, K. H., \& Brannigan, A. (2008). Self-control, child effects, and informal social control: A direct test of the primacy of sociogenic factors. Canadian Journal of Criminology and Criminal Justice, 50, 1-25.

Hay, C. (2001). Parenting, self-control, and delinquency: A test of self-control theory. Criminology, 39, 707-736. 
Hay, C., \& Forrest, W. (2006). The development of self-control: Examining self-control theory's stability thesis. Criminology, 44, 739-774.

Hayslett-McCall, K. L., \& Bernard, T. J. (2002). Attachment, masculinity, and selfcontrol: A theory of male crime rates. Theoretical Criminology, 6, 5-33.

Hawkins, J. D., Farrington, D. P., \& Catalano, R. F. (1998). Reducing violence through schools. In Eilliott, E. D., Hamburg, H. B., \& Williams, K. W. (1998). Violence in American schools. (1 ed.). New York,NY: Cambridge University Press.

Heimer, K. (1996). Sex, interaction, and delinquency: Testing a theory of differential social control. Social Psychology Quarterly, 59, 39-61.

Heimer, K., \& DeCoster, S. (1999). The sexing of violent delinquency. Criminology, 37, $277-312$.

Herrenkohl T.I., Catalano R.F., Hemphill S.A., Toumbourou J.W. (2009). Longitudinal examination of physical and relational aggression as precursors to later problem behaviors in adolescents. Violence and Victims, 24, 3-19.

Higgins, G. E., Jennings, W. G., Tewksbury, R., \& Gibson, C. L., (2009). Exploring the link between low self-control and violent victimization trajectories in adolescence. Criminal Justice and Behavior, 36(10), 1070-1084

Higgins, G. E., Ricketts, M. L., \& Vegh, D. T. (2008). The role or self-control in college student's perceived risk and fear of online victimization. American Journal of Criminal Justice, 33, 223-233.

Higgins, G. E., Wolfe, S. E., \& Marcum, C. D. (2008). Digital piracy: An examination of three measurements of self-control. Deviant Behavior, 29, 440-460.

Higgins, G. E. (2007). Examining the original Grasmick scale: A Rasch model approach. 
Criminal Justice and Behavior, 34(2), 157-178.

Higgins, G. E., \& Tewksbury, R. (2006). Sex and self-control theory: The measures and causal model may be different. Youth and Society, 37(4), 479-503.

Higgins, G. E. \& Ricketts, M. L. (2004). Motivation or opportunity: Which serves as he best mediator in self-control theory? Western Criminology Review, 5(2), 77-96.

Higgins, G. E. (2004). Gender and self-control theory: Are there differences in the measures and the theory's causal model. Criminal Justice Studies, 17(1), 33-55.

Hirschi, T., \& Gottfredson, M.R. (2001). Self-control. In R. Paternoster \& R. Bachman (Eds.), Explaining Crime and Criminals. Los Angeles, CA: Roxbury.

Hope, T. L., Chapple, C. L. (2005). Maternal characteristics, parenting, and adolescent sexual behavior: The role of self-control. Deviant Behavior, 26, 25-45.

Huang B., Kosterman R., Catalano, R.F., Hawkins, J.D., Abbott R.D. (2001) Modeling mediation in the etiology of violent behavior in adolescence: A test of the Social Development Model. Criminology, 39(1), 75-107

Junger-Tas, J., Ribeaud, D., \& Cruyff, M. J. (2004). Juvenile delinquency and sex. European Journal of Criminology, 1, 307-332.

Kim, J., \& Mueller, C. H. (1978). Factor analysis: Statistical methods and practical issues. Newbury Park, California: Sage.

LaGrange, T. C., \& Silverman, R. C. (1999). Low self-control and opportunity: Testing the general theory of crime as an explanation for sex differences in delinquency. Criminology, 37, 41-72.

Lauritsen, J. L., \& Heimer, K. (2008). The sex gap in violent victimization 1973-2004. Journal of Quantitative Criminology, 24, 125-147. 
Longshore, D., Chang, E., Hsieh, S., \& Messina, N. (2004). Self-control and social bonds: A combined control perspective on deviance. Crime \& Delinquency, 50, $542-564$.

Longshore, D. (1998). Self-control and criminal opportunity: A prospective test of general theory of crime. Social Problems, 45, 102-113.

McGloin, J. M., \& Shermer, L. O. (2009). Self-control and deviant peer network structure Journal of Research in Crime and Delinquency, 46, 35-72.

Mason, W. A., \& Windle, M. (2002). Sex, self-control, and informal social control in adolescence: A test of three models of the continuity of deviant behavior. Youth \& Society, 33, 479-514.

Mayer, M. J., \& Furlong, M. J. (2010) How safe are our schools? Educational Researcher 39(1), 16-26.

Mears, D. P., Ploeger, M., \& Warr, M. (1998). Explaining the gender gap in delinquency: Peer influence and moral evaluations of behavior. Journal of Research in Crime and Delinquency, 35(3), 251-266.

Melde, C., \& Esbensen, F. (2009). The victim-offender overlap and fear of in-school victimization: A longitudinal examination of risk assessment models. Crime and Delinquency, 55(4), 499-525.

Meldrum, R. C. (2008). Beyond parenting: An examination of the etiology of self-control. Journal of Criminal Justice, 36, 244-251.

Menard, S. (2002) Applied logistic regression analysis. 2nd ed. Thousand Oaks, CA: Sage 
Mustaine, E. E., \& Tewksbury R. (1998). Predicting risks of larceny theft victimization: A routine activity analysis using refined lifestyle measures. Criminology, 36(4), 829-858.

Nakhaie, M., Silverman, R. A.,\& LaGrange, T. C. (2000). Self-control and social control: An examination of gender, ethnicity, class, and delinquency. Canadian Journal of Sociology, 25,35-39.

Nofziger, S. (2010). A gendered perspective on the relationships between self- control and deviance. Feminist Criminology, 5, 29-50.

Nofziger, S. (2009). Victimization and the general theory of crime. Violence and Victims, $24,337-350$.

Nofziger, S. (2008). The cause of low self-control: The influence of maternal self-control. Journal of Research in Crime and Delinquency. 45(2), 191-224

Paternoster, R., Brame, R., Mazerolle, P., \& Piquero, A. (1998). Using the correct statistical test for the equality of regression coefficients. Criminology, 36, 859866.

Perrone, D., Sullivan, C. J., Pratt, T. C., \& Margaryan, S. (2004).Parental efficacy, selfcontrol, and delinquency: A test of a general theory of crime on a nationally representative sample of youth. International Journal of Offender Therapy and Comparative Criminology, 48, 298-312.

Piquero, A. R., Jennings, W. G., Farrington, D. P. (2010) Self-control interventions for children under age 10 for improving self-control and delinquency and problem behaviors. Campbell Systematic Reviews. 
Piquero, A. R., MacDonald, J. M., Dobrin, A., Daigle, L. E., \& Cullen, F. T. (2005). Self control, violent offending, and homicide victimization: Assessing the general theory of crime. Journal of Quantitative Criminology, 21, 55-71.

Piquero, A.R., Gibson, C.L., \& Tibbetts, S.G. (2002). Does self-control account for the relationship between binge drinking and alcohol-related behaviors? Criminal Behavior \& Mental Health, 12(2), 135-154.

Piquero, A. R., MacIntosh, R., \& Hickman, M. (2000). Does self-control affect survey response? Applying exploratory, confirmatory and item response theory analysis to Grasmick et al.'s self-control scale. Criminology, 38, 897-929.

Popp, A. M., \& Piguero, A. A. (2011). Routine activities and victimization at school: The significance of gender. Journal of Interpersonal Violence, 26(12), 2413-2436.

Pratt, T. C., Cullen, F. T., Sellers, C. S., Winfree, L. T., Madesen, T. D., Diagle, L. E., Fearn, N. E., \& Gau, J. M. (2010). The empirical status of social learning theory: A meta-analysis. Justice Quarterly, 27(6), 765-802.

Pratt, T. C., \& Cullen, F. T. (2000). The empirical status of Gottfredson and Hirschi's general theory of crime: A meta-analysis. Criminology, 38, 931-964.

Pratt, T. C., Turner, M. G. \& Piquero, A. R. (2004). Parental socialization and community context: A longitudinal analysis of the structural sources of low selfcontrol. Journal of Research in Crime and Delinquency, 41, 219-243.

Rand, M. R. (2009). Criminal victimization, 2008. Washington, DC: U.S. Department of Justice Office of Justice Programs, Bureau of Justice Statistics.

Schreck, C. J., Stewart, E. A., \& Fisher, B. S. (2006). Self-control, victimization, and their influence on risky lifestyles: A longitudinal analysis using panel data. 
Journal of Quantitative Criminology, 22, 319-340.

Schreck, C. J., \& Fisher, B. S. (2004). Specifying the influence of family and peers on violent victimization: Extending routine activities and lifestyles theories. Journal of Interpersonal Violence, 19, 1021-1041.

Schreck, C. J., Fisher, B. S., \& Miller, J. M. (2004). The social context of violent victimization: A study of the delinquent peer effect. Justice Quarterly, 21, 23- 48.

Schreck, C. J., Wright, R. A., \& Miller, J. M. (2002). A study of individual and situational antecedents of violent victimization. Justice Quarterly, 19, 159-180.

Schreck, C. J. (1999). Criminal victimization and low self-control: An extension and test of a general theory of crime. Justice Quarterly, 16, 633-654.

Skiba, R., Simmons, A. B., Peterson, R., \& Forde, S. (2006). The SRS safe schools survey: A broader perspective on school violence prevention. In Jimerson, S. R. and Furlong, M. J., Mahwah, New Jersey (eds.), The Handbook of School Violence and School Safety, Lawrence Erlbaum Associates.

Steffensmeier, D., \& Allan, E. (1996). Sex and crime: Toward a sexed theory of female offending. Annual Review of Sociology, 22, 459-487.

Stewart, E., Elifson, K. \& Sterk, C. (2004). Integrating the general theory of crime into an explanation of violent victimization among female offenders. Justice Quarterly, 21, (1), p. 159-181.

Sullivan, C. J., Wilcox, P., \& Ousey, G. C. (2011). Trajectories of victimization from early to mid-adolescence. Journal of Criminal Justice and Behavior, 38(1), 85104.

Terrance, T. J., Peterson, D., Esbensen, F., \& Freng, A. (2007). Gang membership as a 
risk factor for adolescent violent victimization. Journal of Research in Crime and Delinquency, 44(4), 351-380.

Thompson, N. (2010). KR-20. In N. Salkind (Ed.), Encyclopedia of research design. (pp. 668-669). Thousand Oaks, CA: SAGE Publications, Inc.

Tillyer, M.S., Fisher, B. S., \& Wilcox, P. (2011). The effect of school crime prevention on students' violent victimization, risk perception, and fear of crime: A multilevel opportunity perspective. Justice Quarterly, 28(2), 249-277.

Tittle, C.R., \& Botchkovar, E.V. (2005). Self-control, criminal motivation and deterrence: An investigation using Russian respondents. Criminology, 43(2), 307353.

Tittle, C.R., Ward, D.A., \& Grasmick, H.G. (2003). Sex, age, and crime/deviance: A challenge to self-control theory. Journal of Research in Crime \& Delinquency, 40(4), 426-453.

Turner, M. G., Piquero, A. R., \& Pratt, T. C. (2005). The school context as a source of self-control. Journal of Criminal Justice, 33, 327-339.

Turner, M.G., \& Piquero, A.R. (2002). The stability of self-control. Journal of Criminal Justice, 30, 457-471.

Truman, J. L \& Planty, M. (2012). Criminal Victimization, 2011. Washington, DC: U.S. Department of Justice Office of Justice Programs, Bureau of Justice Statistics.

Unnever, J.D., \& Cornell, D. G. (2003). Bullying self-control, and ADHD. Journal of Interpersonal Violence, 18(2), 129-147.

Unnever, J. D., Cullen, F. T., \& Pratt, T. C. (2003). Parental management, ADHD, and delinquent involvement: Reassessing Gottfredson and Hirschi's general theory. 
Justice Quarterly, 20(3), 471-500.

Vazsonyi, A.T., Pickering, L.E., \& Junger, M. (2001). An empirical test of a general theory of crime: A four-nation comparative study of self-control and the prediction of deviance. Journal of Research in Crime \& Delinquency, 38(2), 91131.

Wilcox, P., Tillyer, M. S., Fisher, B. S. (2009). Gendered Opportunity? School-based adolescent victimization. Journal of Research in Crime and Delinquency, 46(2), 245-269.

Winfree, L. T., Taylor, T. J., He, N., \& Esbensen, F. A. (2006). Self-control and variability over time: Multivariate results using a 5-year multisite panel of youths. Crime \& Delinquency, 52, 253-286.

Wood, P., Pfefferbaum, B., \& Arneklev, B. J. (1993). Risk-taking and self-control: Social psychological correlates of delinquency. Journal of Crime and Justice, 16, 111130.

Woodward, L. J., \& Ferguson, D. M. (2000). Childhood and adolescent predictors of physical assault: A prospective longitudinal study. Criminology, 38, 233-261. 
Appendix A:

Self-Control Items 


\section{Impulsivity}

I often act on the spur of the moment without stopping to think

I don't devote much thought and effort to preparing for the future

I often do whatever brings me pleasure here and now, even at the cost of some distant goal

I'm more concerned with what happens to me in the short run than in the long run

\section{Risk-Taking}

I like to test myself every now and then by doing something a little risky

Sometimes I will take a risk just for the fun of it

I sometimes find it exciting to do things for which I might get in trouble

Excitement and adventure are more important to me than security

I lose my temper pretty easily

Often, when I'm angry at people I feel more like hurting them than talking to them about why I am angry

When I'm really angry at people I feel more like hurting them than talking to them about why I am angry

When I have a serious disagreement with someone, it's usually hard for me to talk calmly about it without getting upset

\section{Self-Centeredness}

I try to look out for myself first, even if it means making things difficult for other people

I'm not very sympathetic to other people when they are having problems

If things I do upset people, it's their problem not mine

I will try to get the things I want even when I know it's causing problems for other people 


\section{CURRICULUM VITAE}

NAME:

ADDRESS:
Anthony Aaron Smith

Department of Justice Administration

2311 South $3^{\text {rd }}$ St.

University of Louisville

Louisville, KY 40208

DOB: $\quad$ Louisville, Kentucky - September 9, 1989

EDUCATION

\& TRAINING: $\quad$ B.S. Justice Administration

University of Louisville

2007-2011

AWARDS: $\quad$ Woodcock Society Scholar, 2011

PROFESSIONAL

SOCIETIES: $\quad$ Alpha Phi Sigma Honor Society, 2010 - present

Managing Editor, Journal of Criminal Justice Education

\section{PUBLICATIONS:}

Smith, A., Kirchner, E. E., Higgins, G. E., \& Khey, D. (2011). Trajectories of parenting styles and delinquency: An examination using a sample of African - Americans. TOFAMSJ: The Open Family Studies Journal, 4, 46 - 53. 